\title{
Currency Carry Trades and Funding Risk*
}

\author{
Sara Ferreira Filipe \\ Luxembourg School of Finance
}

Matti Suominen

Aalto University and

Luxembourg School of Finance

\section{December 2013}

\begin{abstract}
In this paper, we measure currency carry trade funding risk using stock market volatility and crash risk in Japan, the main funding currency country. We show that the measures of funding risk in Japan can explain $42 \%$ of the monthly currency carry trade returns during our sample period, 2000-2011. In addition, they explain $64 \%$ of the monthly foreign exchange volatility in our sample of ten main currencies, $28 \%$ of the speculators' net currency futures positions in Australian dollar versus Japanese yen, skewness in currency returns and currency crashes. We present a theoretical model that is consistent with these findings.
\end{abstract}

${ }^{*}$ We would like to thank Harald Hau, Pedro Santa-Clara, Rajnish Mehra, Angelo Ranaldo, Masahiro Watanabe, Alex Kostakis, Rajna Brandon, Petri Jylhä, Kalle Rinne, Melissa Porras Prado and Yoichi Otsubo for very helpful comments. Feedback from seminar participants at INSEAD, EFA 2013 Annual Meeting, Bank of Finland, University of Geneva, Nova University of Lisbon, Luxembourg School of Finance, FMA Europe 2013 Annual Meeting, and the IRF Conference on Japanese Financial Markets is also greatly appreciated. We thank Samu Kilpinen and Peng Xu for excellent research assistance. Comments are welcome at matti.suominen@aalto.fi and sara.ferreira@uni.lu. 
"In most of the world in the past week, attention has been on highly leveraged hedge funds that have been forced to dump assets bought on margin. In Japan, however, a different species of margin trader has - until now, at least - stood firm: the housewife. On her shoulders may lie responsibility for some of the stability of the global financial system....(carry trades) made fortunes for international investors but, lately, Japanese retail investors had become the carry trade's greatest enthusiasts. The metaphorical Mr and Mrs Watanabe account for around 30\% of the foreign-exchange market in Tokyo by value and volume of transactions, according to currency traders, double the share of a year ago. Meanwhile, the size of the retail market has more than doubled to about $\$ 15$ billion a day. One reason for the surge is margin trading. Brokers are offering leverage of as much as 200 times the down-payment (though the average is more like 20 to 40 times). In July Japanese retail investors' short positions on the yen (a bet that it would fall) exceeded the amount taken by traders on the Chicago Mercantile Exchange, a foreign-exchange trading hub. "The gnomes of Zurich were accused in their day of destabilising markets. The housewives of Tokyo are apparently acting to stabilise them," boasted Kiyohiko Nishimura, a Bank of Japan board member, in July." (The Economist, August 2007)

In this paper, we investigate how the financial market conditions in a major carry trade funding country, Japan, affect the global currency markets and currency trading. Although we focus on Japan, our results may apply more generally, as in many cases similar results are obtained in relation to another carry trade funding country, Switzerland. The quote from The Economist above suggests that, first, the popularity of carry trades amongst the Japanese retail investors is large enough so that their collective actions can influence the 
global currency markets. Second, as the Japanese investors use large amount of leverage, those investors' funding availability, and funding risk, are also likely to affect the global currency markets. Besides affecting the currency markets via the Japanese investors, the funding availability and funding risk in yen may affect the currency markets through their effect on the carry trading activities of investors outside the Japan.

We proxy the funding risk in Japanese yen by the options implied stock market volatility and crash risk in the Japanese stock market, estimated using an approach set forth in SantaClara and Yan (2010). There are several reasons to believe that these Japanese equity market risks reflect carry trade investors' yen funding risks, and influence the Japanese and foreign investors' ability and willingness to engage in currency carry trades involving shorting of yen. First, to the extent that the local equity market prices affect the available collateral for local investors at any given point in time, the expected stock market volatility and crash risk in the Japanese equity market reflect risks in the future value of the local investors' collateral. Given this, higher volatility and crash risk in the Japanese stock market reduce the bank's willingness to accept Japanese equity as collateral in their loans to local carry trade investors (collateral is also required when implementing carry trades using forward contracts). Second, as banks in Japan are large investors in the local equity market themselves, see e.g. Franks, Mayer and Miyajima (2013), the Japanese banks' ability to lend money also deteriorates in case of a stock market crash in Japan. This effect is reinforced if the banks' own equity market valuations affect their lending capacity, as argued by Adrian and Shin (2010). Realizing this, investors' willingness to borrow and banks' willingness to lend is likely to be limited when the stock market volatility and crash risk are high. In line with the idea that equity market valuations affect banks' ability to lend, we present evidence in the Appendix that the Japanese financial sector stock market index varies closely with the Japanese banks' 
interbank lending to foreign banks, whose interbank borrowing in turn is tied to carry trades according to Hattori and Shin (2009). ${ }^{1}$

Whatever the relative role of the various channels through which equity market risks in Japan affect the Japanese investors' or other investors' currency market trading, our results suggest that the effects are significant. For instance, during our sample period, from year 2000 to 2011, changes in our estimates of the Japanese equity market volatility and crash risk explain $27 \%$ of the changes in the non-commercial traders' net futures positions in Australian dollar and Japanese yen at the Commodity Futures Trading Commission (CFTC) in the US. These measures can also explain $42 \%$ of monthly carry trade returns, and $64 \%$ of the monthly currency volatility against USD for the average currency in our sample. ${ }^{2}$ Notably, our measures of funding risk in yen explain these currency market phenomena significantly better than measures of funding conditions and funding risk in the US, such as the TED spread and the VIX index, that have been used to explain similar currency market phenomena e.g. in Brunnermeier, Nagel and Pedersen (2009). Our results thus complement the findings in Hattori and Shin (2009), who also demonstrate the importance of Japan for the global currency markets by showing how the conditions in the Japanese interbank market translate into large currency flows in and out of Japan in connection to currency carry trading.

\footnotetext{
${ }^{1}$ The idea that the investors' funding constraints affect asset pricing was first presented in Shleifer and Vishny (1997). See also Gromb and Vayanos (2002) and Brunnermeier and Pedersen (2009). Adrian, Etula, and Muir (2013) show the importance of broker-dealers' leverage in US (a measure of their funding constraints) in explaining the US stock and bond returns.

${ }^{2}$ Our sample consists from ten industrialized countries. When estimating the carry trade returns, we look at the currency carry trades that invest in one to five currencies with the highest interest rates, and borrow in the one to five currencies with the lowest interest rates. In addition, we study separately the most common carry trade according to popular press: borrowing the Japanese yen and investing in the Australian dollar. As is well documented (see e.g. Bekaert, 1996; Burnside, Eichenbaum, Kleshchelski and Rebelo, 2011), such currency carry trades have historically provided good returns to investors due to the failure of the uncovered interest rate parity.
} 
We have several additional results that highlight the importance of the Japanese financial market conditions on global financial markets. We show for instance that the same equity market risks in Japan can explain a large fraction of the time variation in the monthly currency correlations between carry trade investment and funding currencies (e.g. $23 \%$ of the time variation in the correlation between Australian dollar and Japanese yen). In addition, our measures of funding risk can explain skewness in currency returns (particularly for the carry trade investment currencies), as well as currency crash risk. Moreover we show that it is really the Japanese equity market risks that matter, not the equity market risk in general. We stress this result by showing that the equity market risks in Japan (or even in another funding country, Switzerland) make the same measures for US redundant, in regressions explaining carry trade returns.

Our empirical results bridge several earlier findings presented in the literature related to currency carry trade returns and currency market volatility, by showing linkages between funding conditions (as discussed in Brunnermeier, Nagel and Pedersen, 2009) for currency speculators, the volatility in the currency market (as described e.g. in Menkhoff et al., 2012), and currency crash risk (see e.g. Jurek, 2009; Ichiue and Koyama, 2011). Our research provides support for those earlier papers, which argue that the historical returns on currency carry trading reflect limited speculative capital, such as Jylhä and Suominen (2011) and Barroso and Santa-Clara (2012). Furthermore, our results complement the literature linking equity and foreign exchange markets (see for instance Lettau, Maggiori, and Weber, 2013; Hau and Rey, 2005; Korajczyk and Viallet, 1992).

On a broader scope, our paper is related to previous work on the importance of "peso problems" for understanding abnormal returns. Even if market crashes fail to materialize in-sample, it is possible to use forward-looking option prices to estimate implied risk in the 
underlying security and thus measure investors' expectations of such events. Along these lines, Santa-Clara and Yan (2010) use S\&P500 options to estimate US equity market implied risk, and they find support for a "peso problem" explanation of the equity premium puzzle. Here we show that these measures of implied risk in the equity market of a carry trade funding-currency country can explain carry trade returns, therefore supporting a risk-based explanation also for the forward premium puzzle.

To provide structure for our empirical investigation, we set up a stylized model that extends the currency carry trade model presented in Jylhä and Suominen (2011). In our model there are two countries, whose nominal fixed income securities offer different returns due to differences in the two countries' investors' per capita inflation risk. When the correlation between the two countries' inflation risk is high and the number of investors that can engage in international fixed income transactions is small, speculators engage in carry trading. In our model, similarly as in Brunnermeier and Pedersen (2009) and Gromb and Vayanos (2002), speculators face funding constraints. In addition, we assume that there is time variation in the level of funding constraints, causing funding risk. Our model is consistent with the empirical findings discussed above.

Our paper makes two main contributions to the literature. First, it shows how the financial market conditions in a single carry trade short currency can have a significant impact on the global currency markets. Given our results, models that insist on homogenous global investors, or look at currency market phenomena only from a US perspective can only have limited success in empirically explaining the currency market phenomena. Our second contribution is to study theoretically the effects of funding risk on carry trade countries exchange rates, currency return correlations and skewness. 
The rest of the paper is organized as follows. In Section I we present our stylized model. Section II describes the data and Section III discusses the estimation of currency carry trade returns and funding risk. In Section IV we present our empirical findings, while Section V concludes the paper.

\section{The Model}

\section{A. Setup}

Our model builds upon Jylhä and Suominen (2011). We assume that there are two countries $\{i, j\}$, each with $N$ citizens where $N$ is normalized to one. The citizens produce and consume a single commodity and use money in the production of this commodity. We also assume that country $i /$ s production function generates $f_{i}\left(m_{i, t}\right)$ goods in period $t+1$, where $m_{i, t}$ denotes agents' real money holdings of country $i$ 's currency in period $t$. The production function takes the logarithmic form $f_{i}\left(m_{i, t}\right)=A_{i, t} \ln \left(m_{i, t}\right)$, where $A_{i, t}$ denotes the stochastic marginal productivity, known to the agents at time $t$. The marginal productivity, in turn, follows an autoregressive process of the $A R(1)$ form:

$$
A_{i, t}=\overline{A_{i}}-\alpha_{A}\left(A_{i, t-1}-\overline{A_{i}}\right)+\epsilon_{i, t}
$$

where $\overline{A_{i}}$ and $\alpha_{A}$ are positive constants and $\epsilon_{i} \sim N\left(0, \sigma_{A_{i}}^{2}\right)$.

The purchasing power of country $i$ 's money in period $t$ is denoted by $\pi_{i, t}$, so that $M_{i}$ units of country $i$ 's currency have a real purchasing power of $m_{i, t}=M_{i} \pi_{i, t}$. Agents choose their optimal real money holdings given information available at time $t$, thus endogenously determining the purchasing power $\pi_{i, t}$. 
Besides money, there are two other storage technologies in each country. First there is a risk-free asset with real return $r_{f}$ in perfectly elastic supply. We refer to the risk-free asset also as "safe currency". Second, there is a one-period default-free zero coupon bond, sold at a real market price $p_{i, t}$, that pays one unit of country $i$ 's nominal currency at time $t+1$. The risk in this asset comes from the uncertain purchasing power of money in period $t+1, \pi_{i, t+1}$. The expected real return to the country $i$ 's bonds is denoted by $r_{i}=E_{t} \pi_{i, t+1} / p_{i, t}-1$, where $E_{t}$ refers to the expectation operator conditional on time $t$ information. Both countries' risky assets are in zero net supply. As Fama and Farber (1979), we assume that all consumers first hedge their money holdings in the bond market, and only then look at their bond investments. In this case, the effective supply of bonds, denoted in country $i$ 's currency, is country $i$ 's money supply $\bar{M}_{i}$.

We assume overlapping generations of myopic agents, who live for two periods, invest when they are young and consume when they are old. Before dying, they sell their money holdings to the next generation of agents. Period $t$ investors value their next period consumption $c_{t+1}$ using a CARA-utility function, $u\left(c_{t+1}\right)=-E_{t} e^{-a c_{t+1}}$, where $a$ denotes risk aversion. Furthermore, let us denote by $b_{i, t}$ the quantity of country $i$ 's nominal zero coupon bonds, with a face value of one, that an agent purchases (or sells) in period $t$ (in addition to his short position in country $i$ 's bonds, that comes from hedging his currency holdings). Similarly, let $b_{j, t}$ refer to purchases of country $j$ 's bonds.

We assume that the financial markets are segmented: a fraction $\left(1-k_{i}\right)>0$ of country $i$ 's investors have prohibitively high transaction costs of investing abroad, i.e. to hold money or interest bearing securities in a foreign currency. Fraction $k_{i}$ of country $i$ 's investors, on the other hand, are unrestricted. We call the restricted investors "domestic investors" 
and the unrestricted ones "speculators". 3 To keep the model parsimonious, in contrast to Jylhä and Suominen (2011), we take the number of speculators as given. ${ }^{4}$ Our second point of departure from Jylhä and Suominen (2011) is to assume that investors face borrowing constraints, as in Brunnermeier and Pedersen (2009) and Gromb and Vayanos (2002). The main innovation in our model, however, is to assume time variation in the severity of the borrowing constraints. We assume that the borrowing constraint for country $i$ bonds at time $t$ is given by $b_{i, t} \geq-h_{i, t}$, with $h_{i, t}>0$. Furthermore, evaluated at time $t$, the next period's borrowing constraint is random:

$$
h_{i, t+1}=\bar{h}-\alpha_{h}\left(h_{i, t}-\bar{h}\right)+\delta_{i, t+1}
$$

where $\bar{h}$ and $\alpha_{h}$ are positive constants and $\delta_{i, t} \sim N\left(0, \sigma_{h}^{2}\right)$. For simplicity, we assume that $\delta_{i, t}$ is independent of $\epsilon_{i, t}$. Without loss of generality, we assume $\alpha_{A}=\alpha_{h}=\alpha$. Given condition (2), in our model the investors face not only funding constraints, but also funding risk. In contrast to the financial markets, there are no barriers in the product market.

Therefore, assuming that period $t$ investors are endowed with a real wealth $w_{t}$ at the beginning of period $t$, country $i$ 's speculators at time $t$ maximize:

$$
\begin{aligned}
\underset{m_{i, t}, b_{i, t}, b_{j, t}}{\operatorname{Max}}-E_{t} e^{-a c_{t+1}} \quad \text { s.t. } \\
c_{t+1}=\left(w_{t}-m_{i, t}+p_{i, t} \frac{m_{i, t}}{\pi_{i, t}}\right)\left(1+r_{f}\right)+f_{i}\left(m_{i, t}\right)+\sum_{n=i, j} b_{n, t}\left(\pi_{n, t+1}-p_{n, t}\left(1+r_{f}\right)\right) \\
b_{i, t} \geq \quad-h_{i, t}, \quad b_{j, t} \geq-h_{j, t} .
\end{aligned}
$$

\footnotetext{
${ }^{3}$ The domestic investors' transaction costs from investing abroad can also be behavioral.

${ }^{4}$ Jylhä and Suominen (2011) study a model where the number of speculators is endogenous and assume that investors must pay a fee $\Phi>0$ to obtain access to international money markets.
} 
The domestic investors in country $i$, in turn, solve the following optimization problem:

$$
\begin{aligned}
& \underset{m_{i, t}, b_{i, t}}{\operatorname{Max}}-E_{t} e^{-a c_{t+1}} \quad \text { s.t. } \\
c_{t+1}= & \left(w_{t}-m_{i, t}+p_{i, t} \frac{m_{i, t}}{\pi_{i, t}}\right)\left(1+r_{f}\right)+f_{i}\left(m_{i, t}\right)+b_{i, t}\left(\pi_{i, t+1}-p_{i, t}\left(1+r_{f}\right)\right) \\
b_{i, t} \geq & -h_{i, t} .
\end{aligned}
$$

Equilibrium prevails when each agent's action maximizes his expected utility and markets clear. Finally, note that country $i$ 's citizens do not benefit from country $j$ 's currency in their production activities.

\section{B. The Equilibrium}

\section{B.1. Equilibrium Conditions}

Since there are no restrictions in the product market, purchasing power parity (PPP) implies that the period $t$ exchange rate (at which country $j$ 's currency can be exchanged to country $i$ 's currency) is given by $S_{t}^{j, i}=\pi_{j, t} / \pi_{i, t}$. We will for the moment assume that the borrowing constraints do not bind for the domestic investors. We later verify this assumption. Now, define $M_{i, t}^{d}$ as the per capita supply of country $i$ 's zero coupon bonds that must, in equilibrium, be purchased by the domestic investors of country $i$. We use a superscript $d$ to denote a domestic investor and a superscript $s$ to denote a speculator. In other words, if the speculators hold $k_{i} b_{i, t}^{s, i}+k_{j} b_{i, t}^{s, j}$ units of country $i$ 's bonds (where the sub-index $i$ in $b_{i, t}^{s, j}$ refers 
to the country in whose currency the investment is made and the superscript $j$ refers to the country where speculator $s$ is originally from), we define $M_{i, t}^{d}$ as:

$$
M_{i, t}^{d}=\frac{\bar{M}_{i}-k_{i} b_{i, t}^{s, i}-k_{j} b_{i, t}^{s, j}}{1-k_{i}}
$$

We will now assume (and verify later) that $\pi_{i, t}$ and $\pi_{j, t}$ are jointly normally distributed with means $\bar{\pi}_{k}$ and variances $\sigma_{k}^{2}$, where $k \in\{i, j\}$. Taking expectations and the first order condition of (4) with respect to domestic investors' bond holdings $b_{i, t}^{d}$, and using the market clearing condition $b_{i, t}^{d}=M_{i, t}^{d}$, we obtain that the price of the zero coupon bond, $p_{i, t}$, in country $i$ at time $t$ is:

$$
p_{i, t}\left(1+r_{f}\right)=E_{t} \pi_{i, t+1}-a \sigma_{i}^{2} M_{i, t}^{d}
$$

where $\sigma_{i}^{2} \equiv \operatorname{var}\left(\pi_{i, t+1}\right)$ denotes the variance of the purchasing power of country $i$ 's currency (conditional on time $t$ information). This implies that the Sharpe ratio for the real returns on country $i$ 's bonds is:

$$
S R_{i, t}=\frac{r_{i, t}-r_{f}}{\sigma_{i} / p_{i, t}}=a \sigma_{i} M_{i, t}^{d}
$$

These results show that the Sharpe ratio on bond investments is increasing in the parameter of risk aversion $a$, inflation risk $\sigma_{i}$, and the per capita supply of bonds in the domestic market $M_{i, t}^{d}$. In the case of an autarky, where $k_{i}$ and $k_{j}$ are zero, $M_{i, t}^{d}=\bar{M}_{i}$, where $\bar{M}_{i}$ is the local money supply. In such perfectly segmented markets, the Sharpe ratio for bonds is higher in the country with the higher per capita inflation risk, $\bar{M}_{i} \sigma_{i}$. Let us denote by $H$ the country with the higher per capita inflation risk and by $L$ the country with the lower per capita inflation risk. In the case of autarkies, the higher Sharpe ratio in country $H$, as 
compared to country $L$, is necessary to attract sufficient investment into the risky bonds of country $H$, clearing the market despite the higher amount of risk being sold.

Let us now look at the speculators' problem. Taking the first order condition of (3) with respect to the speculators' investment into country $i$ 's bonds, $b_{i, t}^{s}$, implies:

$$
b_{i, t}^{s}=\frac{E_{t} \pi_{i, t+1}-p_{i, t}\left(1+r_{f}\right)-b_{j, t}^{s} a \rho \sigma_{i} \sigma_{j}+\lambda_{i, t} / a}{a \sigma_{i}^{2}}
$$

where $\rho \equiv \operatorname{corr}_{t}\left(\pi_{i, t+1}, \pi_{j, t+1}\right)$ equals the correlation between the two countries' purchasing power, and $\lambda$ denotes the Lagrangian multiplier, so that $\lambda_{i, t} \geq 0$ and $\lambda_{i, t}\left(b_{i, t}^{s}+h_{i, t}\right)=0$. Again, the $i$ and $j$ sub-indices refer to the currency in which the investment is made. There is no superscript for countries, as the speculators from both countries make similar investments. Using (5) and (6) in (8), we can now solve for the equilibrium bond holdings.

Next, recall that $f_{i}\left(m_{i, t}\right)=A_{i, t} \ln \left(m_{i, t}\right)$. Taking the first order condition of (3) and (4) with respect to $m_{i, t}$ and, using it together with condition (6), implies:

$$
E_{t} \pi_{i, t+1}=\left(1+r_{f}\right) \pi_{i, t}-\frac{A_{i, t}}{\bar{M}_{i}}+a \sigma_{i}^{2} M_{i, t}^{d}
$$

From conditions (6) and (9), the exchange rate can now be stated as a function of the two countries zero-coupon bond prices:

$$
S_{t}^{j, i}=\frac{\pi_{j, t}}{\pi_{i, t}}=\frac{p_{j, t} \bar{M}_{i} \bar{M}_{j}\left(1+r_{f}\right)+A_{j, t} \bar{M}_{i}}{p_{i, t} \bar{M}_{i} \bar{M}_{j}\left(1+r_{f}\right)+A_{i, t} \bar{M}_{j}} .
$$

\section{B.2. The Equilibrium}

The higher Sharpe ratio in country H's bonds implies that speculators are always long in these bonds. Therefore the borrowing constraint is potentially binding only for country $L$ 
bonds. We next characterize our economy in two states: 1) the borrowing constraints do not bind and 2) the speculators' borrowing constraint in country $L$ is binding. In the region where the funding constraints bind occasionally we solve the model using numerical methods.

Case 1: Borrowing constraint is not binding The equilibrium is the same as in Jylhä and Suominen (2011). ${ }^{5}$ Solving the set of equations (5), (6), and (8) with $\lambda_{i, t}=0$, we obtain that in equilibrium all speculators hold identical portfolios:

$$
b_{i}^{s, U}=\frac{\bar{M}_{i} \sigma_{i}\left(1+k_{i}\right)-\bar{M}_{j} \sigma_{j} \rho\left(1-k_{i}\right)}{\sigma_{i}\left[\left(1-\rho^{2}\right)\left(1+k_{i} k_{j}\right)+\left(1+\rho^{2}\right)\left(k_{i}+k_{j}\right)\right]}
$$

of country $i$ 's bonds, while the domestic investors hold:

$$
b_{i}^{d, U}=M_{i}^{d, U}=\frac{\bar{M}_{i} \sigma_{i}\left(1+k_{i}-\rho^{2}+\rho^{2} k_{j}\right)+\bar{M}_{j} \sigma_{j} \rho\left(k_{i}+k_{j}\right)}{\sigma_{i}\left[\left(1-\rho^{2}\right)\left(1+k_{i} k_{j}\right)+\left(1+\rho^{2}\right)\left(k_{i}+k_{j}\right)\right]}
$$

of such bonds. The superscript $U$ refers to the unconstrained equilibrium. Using (12) in equations (6) and (7) gives us an easy characterization of the equilibrium bond prices and Sharpe ratios in our economy.

Note from (12) that, in both countries, the supply of bonds that domestic investors hold is strictly positive (therefore verifying our earlier assumption that domestic investors are long in bonds) and implying also positive Sharpe ratios. Note also from (11) that, in equilibrium, the speculators are indeed always long in country $H$ 's bonds. Moreover, if $\rho$ is high enough, i.e., $\rho>\bar{\rho}$ with $\bar{\rho} \equiv\left(\bar{M}_{L} \sigma_{L}\right) /\left(\bar{M}_{H} \sigma_{H}\right)$, and $k_{L}$ is small enough, i.e., $k_{L}<\bar{k}_{L}$ with $\bar{k}_{L} \equiv\left(\bar{M}_{H} \sigma_{H} \rho-\bar{M}_{L} \sigma_{L}\right) /\left(\bar{M}_{H} \sigma_{H} \rho+\bar{M}_{L} \sigma_{L}\right)$, the speculators are short the country

\footnotetext{
${ }^{5}$ This unconstrained equilibrium is stable for sufficiently high $\bar{h}$ and sufficiently small $\sigma_{h}$. In this region, the borrowing constraint becomes binding only if a sudden funding crash occurs, i.e. there is a sharp decline in $h_{L}$. Since the probability of this tail event can be made arbitrarily small, we follow the usual practice in the literature and neglect it in the solution of case 1.
} 
$L$ bonds, thus engaging in a carry trade. For the remainder of the paper, we will assume $\rho>\bar{\rho}$ and $k_{L}<\bar{k}_{L}$.

Case 2: Borrowing constraint in country $L$ is binding For sufficiently low $\bar{h}$ and sufficiently low $\sigma_{h}$, it is easy to show that equations (5), (6), and (8) imply a constrained equilibrium where the speculators' borrowing constraint in country $L$ is binding and speculators still enter into a carry trade. ${ }^{6}$ In such an equilibrium, using conditions (9) and (8) we have:

$$
\begin{aligned}
b_{L, t}^{s, C} & =-h_{L, t}, \\
b_{H, t}^{s, C} & =\frac{\bar{M}_{H}}{1+k_{L}}+\frac{\left(1-k_{H}\right) \rho \sigma_{L}}{\left(1+k_{L}\right) \sigma_{H}} h_{L, t},
\end{aligned}
$$

which, together with condition (6), imply:

$$
\begin{aligned}
& \left(1+r_{f}\right) p_{L, t}=E_{t} \pi_{L, t+1}-a \sigma_{L}^{2}\left(\frac{\bar{M}_{L}+\left(k_{L}+k_{H}\right) h_{L, t}}{1-k_{L}}\right), \\
& \left(1+r_{f}\right) p_{H, t}=E_{t} \pi_{H, t+1}-a \sigma_{H}^{2}\left(\frac{\bar{M}_{H}}{1+k_{L}}-\frac{\left(k_{L}+k_{H}\right) \rho \sigma_{L}}{\sigma_{H}\left(1+k_{L}\right)} h_{L, t}\right) .
\end{aligned}
$$

The superscript $C$ refers to the constrained equilibrium. From condition (13), we can see that stricter funding constraints (lower $h_{L}$ ) lead to a smaller $b_{H}^{s}$ and larger (i.e. smaller in absolute value) $b_{L}^{s}$. Moreover, in such an equilibrium, the bond investments of domestic investors $b_{L}^{d}$ and $b_{H}^{d}$ remain positive.

Case 3: Borrowing constraint in country $L$ is occasionaly binding In solving the model for cases 1 and 2, we have to assume that either the borrowing constraint is always

\footnotetext{
${ }^{6}$ In this region, the borrowing constraint can be made binding with probability close to 1 . As above, we neglect tail events in solving for the constrained equilibrium.
} 
binding, or it is never binding. Under Normal distribution for the borrowing constraint and under suitable parameters for the model, these assumptions can hold with a probability arbitrarily close to one. For other parameter selections, the assumption that borrowing constraints always hold or never hold are too stringent to even approximately characterize the equilibrium. In those cases, we must resort to numerical solutions for the model. In the Appendix B we derive six equilibrium conditions, that allow us to numerically solve for the equilibrium.

\section{Model Predictions}

In this subsection, we turn to the model implications, in terms of the effect of funding conditions and funding risk on exchange rates and speculators' activity.

\section{C.1. Exchange Rate Volatility and Correlations}

Hypothesis 1: When the borrowing constraint in the carry trade funding currency is binding, exchange rate volatility (relative to the safe currency) is higher for both risky currencies, compared to the region where the borrowing constraint is not binding. In addition, higher funding risk, $\sigma_{h}$, increases currency volatility. Given the structure of the shocks in the model, we conjecture and verify that the purchasing power $\pi$ also follows an auto-regressive process and thus its conditional expectation depends on the current value according to $E_{t} \pi_{i, t+1}=\bar{\pi}_{i}-\alpha_{\pi, i}\left(\pi_{i, t}-\bar{\pi}_{i}\right)$, with $\bar{\pi}_{i}$ constant. Using condition (9), we can therefore determine $\bar{\pi}_{i}$ and $\alpha_{\pi, i}$ as functions of the underlying parameters. In the case of the non-binding borrowing constraint, this implies:

$$
\pi_{i, t}^{U}=\bar{\pi}_{i}^{U}+\frac{A_{i, t}-\overline{A_{i}}}{\bar{M}_{i}\left(1+r_{f}+\alpha\right)},
$$


where $U$ denotes the unconstrained equilibrium, and

$$
\bar{\pi}_{i}^{U}=\frac{\overline{A_{i}}}{r_{f} \bar{M}_{i}}-\frac{a M_{i}^{d, U}\left(\sigma_{i}^{2}\right)^{U}}{r_{f}} .
$$

Given that condition (9) also holds for both countries in the case where the constraints are binding, similar arguments yield:

$$
\begin{aligned}
\pi_{L, t}^{C} & =\bar{\pi}_{L}^{C}+\frac{A_{L, t}-\overline{A_{L}}}{\bar{M}_{L}\left(1+r_{f}+\alpha\right)}-\frac{a\left(\sigma_{L}^{2}\right)^{C}\left(k_{L}+k_{H}\right)\left(h_{L, t}-\bar{h}\right)}{\left(1-k_{L}\right)\left(1+r_{f}+\alpha\right)}, \\
\pi_{H, t}^{C} & =\bar{\pi}_{H}^{C}+\frac{A_{H, t}-\overline{A_{H}}}{\bar{M}_{H}\left(1+r_{f}+\alpha\right)}+\frac{a \sigma_{L}^{C} \sigma_{H}^{C} \rho^{C}\left(k_{L}+k_{H}\right)\left(h_{L, t}-\bar{h}\right)}{\left(1+k_{L}\right)\left(1+r_{f}+\alpha\right)},
\end{aligned}
$$

where:

$$
\begin{aligned}
\bar{\pi}_{L}^{C} & =\frac{\overline{A_{L}}}{r_{f} \bar{M}_{L}}-\frac{a E\left(M_{L, t}^{d, C}\right)\left(\sigma_{L}^{2}\right)^{C}}{r_{f}}=\frac{\overline{A_{L}}}{r_{f} \bar{M}_{L}}-\frac{a\left(\sigma_{L}^{2}\right)^{C}\left[\bar{M}_{L}+\left(k_{L}+k_{H}\right) \bar{h}\right]}{r_{f}\left(1-k_{L}\right)} \\
\bar{\pi}_{H}^{C} & =\frac{\overline{A_{H}}}{r_{f} \bar{M}_{H}}-\frac{a E\left(M_{H, t}^{d, C}\right)\left(\sigma_{H}^{2}\right)^{C}}{r_{f}}=\frac{\overline{A_{H}}}{r_{f} \bar{M}_{H}}+\frac{a \sigma_{L}^{C} \sigma_{H}^{C} \rho^{C}\left(k_{L}+k_{H}\right) \bar{h}}{r_{f}\left(1+k_{L}\right)}-\frac{a\left(\sigma_{H}^{2}\right)^{C} \bar{M}_{H}}{r_{f}\left(1+k_{L}\right)} .
\end{aligned}
$$

Again $C$ denotes the constrained equilibrium. Using these conditions for the purchasing power, we can calculate the corresponding variances (conditional on time $t$ information) for the non-binding case:

$$
\operatorname{Var}_{t}\left(\pi_{i, t+1}^{U}\right) \equiv\left(\sigma_{i}^{2}\right)^{U}=\frac{\sigma_{A_{i}}^{2}}{\left[\bar{M}_{i}\left(1+r_{f}+\alpha\right)\right]^{2}},
$$


and for the binding case:

$$
\begin{aligned}
& \operatorname{Var}_{t}\left(\pi_{L, t+1}^{C}\right) \equiv\left(\sigma_{L}^{2}\right)^{C}=\left(\sigma_{L}^{2}\right)^{U}+\left(\frac{a\left(k_{L}+k_{H}\right) \sigma_{h}\left(\sigma_{L}^{2}\right)^{C}}{\left(1-k_{L}\right)\left(1+r_{f}+\alpha\right)}\right)^{2}>\left(\sigma_{L}^{2}\right)^{U}, \\
& \operatorname{Var}_{t}\left(\pi_{H, t+1}^{C}\right) \equiv\left(\sigma_{H}^{2}\right)^{C}=\left(\sigma_{H}^{2}\right)^{U}+\left(\frac{a \sigma_{L}^{C} \sigma_{H}^{C} \rho^{C}\left(k_{L}+k_{H}\right) \sigma_{h}}{\left(1+k_{L}\right)\left(1+r_{f}+\alpha\right)}\right)^{2}>\left(\sigma_{H}^{2}\right)^{U} .
\end{aligned}
$$

Equation (20) shows that the volatilities of the two countries' purchasing power and, given this, also the volatilities of their exchange rates with respect to the risk-free asset, are higher in the constrained case. In addition, they increase with $\sigma_{h}{ }^{7}$

Hypothesis 2: When the borrowing constraint is binding, the correlation between the purchasing powers in carry-long and -short countries is lower. In addition, higher funding risk, $\sigma_{h}$, decreases this correlation. Using conditions (15) and (17) above, we can calculate how the correlation between the two countries' purchasing power varies between the unconstrained and constrained equilibria and, in the latter case, how it varies with funding risk. For the unconstrained equilibrium, we have:

$$
\operatorname{Corr}_{t}\left(\pi_{i, t+1}^{U}, \pi_{j, t+1}^{U}\right) \equiv \rho^{U}=\frac{\sigma_{A_{i}, A_{j}}}{\sigma_{A_{i}} \sigma_{A_{j}}}=\rho_{A}
$$

while, for the constrained equilibria, conditions (17) and (18) imply that:

$$
\operatorname{Corr}_{t}\left(\pi_{i, t+1}^{C}, \pi_{j, t+1}^{C}\right) \equiv \rho^{C}=\frac{\rho^{U}}{\frac{\sigma_{L}^{C} \sigma_{H}^{C}}{\sigma_{L}^{U} \sigma_{H}^{U}}\left[1+\frac{\left(a \sigma_{L}^{C}\left(k_{L}+k_{H}\right) \sigma_{h}\right)^{2}}{\left(1-k_{L}^{2}\right)\left(1+r_{f}+\alpha\right)^{2}}\right]}<\rho^{U}
$$

\footnotetext{
${ }^{7}$ Note that condition (20) implies that there can exist two different constrained equilibria with different volatilities (and, in both cases, $\sigma_{i}^{C}$ is higher than $\sigma_{i}^{U}$ ).
} 
Thus, the correlation between carry-long and -short currencies - where each currency is measured vis-a-vis the risk-free asset - is lower when borrowing constraints are binding. Moreover condition (22), along with condition (20), shows that $\rho^{C}$ is decreasing in funding

risk, $\sigma_{h}^{2}$. The lower correlation between the carry trade long and the carry trade short currencies, in the region where the funding constraints bind, is caused by the time variation in the severity of the funding constraints. Whenever the funding constraints tighten, the speculators unwind their carry trade positions, buying carry trade short currencies and selling carry trade long currencies, thus pushing the two currencies in opposite directions. Similarly, when the funding conditions are relaxed, they buy the carry trade long currencies and short the carry trade short currencies, again pushing the currencies in opposite directions.

\section{C.2. Skewness and Currency Crashes}

\section{Hypothesis 3: Tightening of funding conditions is associated with exchange rate} skewness and currency crashes To demonstrate what happens as the funding constraints become tighter, we must resort to the numerical solution of the model. The development of the two currencies expected exchange rates to the safe currency are depicted in Figure 1 for the special case where $\alpha$ equals zero.

[Figure 1 here]

Our model makes predictions on currency skewness. In the region where the constraints are not binding, the exchange rate fluctuations are smaller, given (20), therefore leading to skewness in currency returns. In addition, our numerical solutions, as the one presented in Figure 1, suggest that the sign of the skewness for the investment currencies is negative, while the sign of the skewness for the funding currencies is likely to be positive. 
Under some parameter values, our simulations predict that there would be a drop in the value of both of the risky currencies (currency crash) when the funding constraints start binding. To understand the possibility of such a currency crash, it is useful to compare the two equilibria where the funding constraints either always bind, or never bind. Note that, from the proof to Hypothesis 1, the currency variances are higher in the constrained equilibrium. Given Equations (16) and (18), other things equal, this alone should lead to a decline in the values of the purchasing power of both currencies (i.e., a currency crash) when the economy switches from a region where the funding constraints do not bind to a region where they bind. In our model, the currencies price variability is higher in the constrained equilibrium, because there is constant portfolio rebalancing by the speculators in response to changes in the borrowing constraints. Additional desire for portfolio rebalancing when the borrowing constraint starts binding comes from a change in the correlation between the two risky currencies implied by (22).

\section{C.3. Speculative Activity and Currency Carry Trade Returns}

\section{Hypothesis 4: The level of the funding constraints and funding risk affect spec-} ulators' positions It is clear from equations (13) that the level of funding constraints in country $L, h_{L}$, directly affects the amount of country $L$ bonds that speculators can short. In addition, it affects the amount of speculators' investment in country $H$. Moreover, in the region where the constraint is binding, conditions (13) and (22) imply that the funding risk, $\sigma_{h}$, reduces speculative investment in currency $H$, therefore leading to unwinding of long-side carry trades. Both effects confirm hypothesis 4 . 


\section{Hypothesis 5: The level of the funding constraints and funding risk affect carry}

trade returns From condition (17) we see that, in the region where the funding constraints bind, decreases in $h_{L}$ (i.e., tightening of the funding constraints) lead to an increase in currency $L$ and a decrease in currency $H$, thus affecting adversely carry trade returns. Furthermore, from (17) and (22) we can see that increases in funding risk, $\sigma_{h}$, lead to disproportionate decreases in the values of both risky currencies, also affecting currency carry trade returns.

\section{The Data}

\section{A. Currency Data}

Exchange rate data for the period between January 2000 and December 2011 is collected from Reuters (WM/R) at Datastream. It includes daily spot rates, as well as 1-month forward rates, and all quotes are expressed as foreign currency units (FCU) per USD. Following Lustig et al. (2011) or Menkhoff et al. (2012), we focus on a sample of ten developed countries: Australian dollar (AUD), Canadian dollar (CAD), Danish krone (DKK), Euro (EUR), Japanese yen (JPY), New Zealand dollar (NZD), Norwegian krone (NOK), Swedish krona (SEK), Swiss franc (CHF) and UK pound (GBP).

As a proxy for carry trade activity, we follow Brunnermeier et al. (2009) and use the futures position data from the Commodity Futures Trading Commission (CFTC), available at a weekly frequency. 


\section{B. Stock Market Options Data}

For the estimation of funding risk, we use data on European options of stock market indices from four different countries - US, Australia, Japan and Switzerland. For the US, we use data on S\&P 500 index options traded on the Chicago Board Options Exchange (CBOE); for Australia, data on S\&P/ASX 200 index options traded on Australian Stock Exchange (ASX); for Japan, data on Nikkei 225 index options traded on Osaka Securities Exchange (OSA); and, for Switzerland, data on SMI 50 index options traded on Eurex (EUX). US and Japanese samples start in January 2000, while the series for Australia and Switzerland start in February and July 2001, respectively. All options are traded in local currency and we use end-of-day data obtained from Thomson Reuters. The stock market indices and LIBOR interest rates for different maturities (from 1 week to 1 year) are also obtained from Datastream.

Starting with daily data on the different stock index options, we first apply a similar filtering process as Santa-Clara and Yan (2010). We drop contracts with missing data; maturity is restricted to be longer than 10 days and shorter than 1 year; we keep only options with moneyness (i.e. stock price divided by the strike price) between 0.85 and 1.15; cases with open interest of fewer than 100 contracts are excluded (except for ASX200 options, for which this information is mostly non-available); we use only put options and apply option parity to obtain the corresponding call prices; contracts that have too low prices are excluded ${ }^{8}$; cases that imply option mispricing (i.e. violation of boundary conditions) are also dropped. For the remaining sample, we calculate Black-Scholes implied volatilities and delete those contracts for which this value cannot be determined. In Appendix, Table A.1

\footnotetext{
${ }^{8}$ Following Santa-Clara and Yan (2010), the cutoff price is 0.125 USD for S\&P500. In similar fashion, we choose 12.5 Yen for Nikkei225, 0.1875 AUD for ASX200 and 0.125 SWF for SMI50.
} 
shows the mean implied volatilities, as well as the numbers of option contracts for each market.

\section{Modeling Carry Trade Returns and Funding Risk}

In this section, we first present the carry trade strategy and associated returns for different portfolio constructions. Second, we present our proxies for funding risk.

\section{A. The Returns to Currency Carry Trade}

The carry trade investor borrows in low interest rate currencies and invests in high interest rate currencies, thus making positive expected returns due to the failure of the uncovered interest rate parity. The carry trade can also be implemented using forward exchange rate contracts (see for example Galati et al., 2007). Following this latter approach, we calculate monthly returns using one-month forward rates. We first sort currencies according to their forward discounts ${ }^{9}$, and then borrow (invest in) the currency with the smallest (largest) forward discount. We denote this long-short strategy by $H m L$ (High-minus-Low). During our sample period, Japanese yen and Swiss franc were typically considered the standard "funding currencies", while Australian and New Zealand dollars were the two major "investment currencies". Therefore a very popular strategy among investors was to short the Japanese yen and go long the Australian dollar. We consider this strategy, which we denote by AUmJP (Australian dollar minus Japanese yen), and present its return over time on Figure 2.

[Figure 2 here]

\footnotetext{
${ }^{9}$ The forward discount is defined as $F D=f w / e-1$, where $e$ is the spot exchange rate (denominated in FCU's per USD) and $f w$ is the forward exchange rate.
} 
For robustness purposes, we also consider two alternative strategies: going long (short) in the three currencies with the three largest (smallest) forward discounts (HmL3); going long (short) in the five currencies with the five largest (smallest) forward discounts ( $H m L 5)$.

Table I shows the summary statistics of the monthly returns on these carry trade portfolios. Compared to our estimates, Menkhoff et al. (2012) report a higher average return for the period covering December 1983 to August 2009. This difference is consistent with the findings of Jylhä and Suominen (2011), who find that carry trade returns have decreased over time.

\section{[Table I here]}

\section{B. Estimating Funding Risk}

\section{B.1. Motivation}

We proxy for the carry trade funding risk in any given country's currency by the options implied volatility and crash risk in that country's stock market. More specifically, we estimate the options' implied stock market volatility and jump intensity for selected countries' stock markets using data on the respective markets' equity index options. As we argued in the Introduction, there are several reasons to believe that these measures reflect funding risks for the local investors speculating in the international currency markets, as well as for the international investors who borrow in the local currency. First, local equity is commonly used as a collateral when local investors fund their currency carry trades. Hence local equity market risks pose risks in the amount of collateral that local investors can pledge in the future. Second, local equity market risks cause risks in the banks' ability to lend: banks in many countries (for instance in Japan) are large investors in the local equity market. Hence 
changes in local equity market valuations directly affect the banks' capital requirements and lending capacity. Furthermore, irrespective of the former, as Adrian and Shin (2010) argue, in a financial system where balance sheets are continuously marked to market, reductions in banks' own equity market valuation affect their ability to lend. Through these channels, risks in the local equity market translate to funding risks to all investors who rely on funding from the local financial intermediaries. The funding risks can be largely currency-specific, since stresses on the local banks' balance sheets can cause shortage of funding especially in the local currency (see also McGuire and von Peter, 2009). As Japanese yen is the most significant funding currency in carry trades, and carry trading is popular among the Japanese retail investors, we focus on the functioning of the Japanese financial markets and the associated potential shortages of yen funding.

There exists some evidence that the local financing conditions in Japan affect international banks' customers carry trading. Hattori and Shin (2009) present evidence that there is significant time variation in the availability of yen funding that is closely connected to the popularity of the yen carry trade. Following Hattori and Shin (2009), we also show for our sample period (in Appendix A) that there is significant comovement between the net interbank assets of foreign banks of Japan (i.e., the difference in the interbank lending and borrowing by foreign banks in Japan), their net interoffice accounts (i.e., the net liabilities of the parent offices due to their foreign-related offices), and carry trade activity. First, there is a strongly negative correlation, $-65.10 \%$, between the net interbank assets and the net interoffice accounts of foreign banks in Japan (see Figure A.1). As Hattori and Shin (2009), we interpret this to be evidence that the foreign banks channel yen funding out of Japan through their local subsidiaries. To show further support for the idea that funding conditions in Japan affect the carry trade activity of the foreign banks, and their customers, 
we show that these foreign banks' net interoffice accounts are closely related to the carry trade activity in Japanese yen futures (see Figure A.2). Our evidence therefore suggests that, in times when the carry trade positions are actively taken and speculators short the yen futures in the US, the foreign banks' subsidiaries simultaneously increase their borrowing in the Japanese interbank market, and lend out yen to their parent companies. Moreover, and in line with the arguments presented in Adrian and Shin (2010), that the market value of the local banks' equity affects their ability to lend out money, we find a striking relation between the equity prices of Japanese financial institutions and their yen lending to foreign financial institutions, as depicted in Figure A.3. This is evidence that the foreign bank's ability to obtain yen funding depends on the health of the Japanese banks, and in particular on their equity market valuations.

\section{B.2. Our Measure of Funding Risk}

We use index option data to estimate stock market risk (both diffusion and jump components) as it is perceived ex ante by investors. Our goal is to relate these measures, estimated for both long and short carry countries, with exchange rate dynamics and speculators' activity. For this purpose, we consider four markets: the US (the benchmark currency), Australia (a typical 'investing currency', in which investors go long $)^{10}$, as well as Japan and Switzerland (the typical 'funding currencies', commonly shorted by speculators). However, in most of our empirical analysis, we focus on the funding risk in Japan, as the Japanese Yen was the most important funding currency during our sample period.

We follow Santa-Clara and Yan (2010) and model stochastic volatility as a Brownian motion and the jump risk as a Poisson process, which is assumed to have stochastic intensity.

\footnotetext{
${ }^{10}$ Another natural candidate for a long currency would be New Zealand. However data on stock index options for this country is not available, thus restricting our sample choice.
} 
In particular, for each of the four countries above, the dynamics of the stock market index $S$ is modeled as follows:

$$
\begin{aligned}
d S & =\left(r+\phi-\lambda \mu_{Q}\right) S d t+Y S d W_{S}+Q S d H \\
d Y & =\left(\mu_{Y}+\kappa_{Y} Y\right) d t+\sigma_{Y} d W_{Y} \\
d Z & =\left(\mu_{Z}+\kappa_{Z} Z\right) d t+\sigma_{Z} d W_{Z} \\
\ln (1+Q) & \sim \mathrm{N}\left(\ln \left(1+\mu_{Q}\right)-\frac{1}{2} \sigma_{Q}^{2}, \sigma_{Q}^{2}\right) .
\end{aligned}
$$

Here $r$ is the constant risk-free interest rate. The diffusive variance of the stock return is $\nu=Y^{2}$. $H$ is a Poisson process, such that $\operatorname{Pr}(d H=1)=\lambda d t$, where the stochastic arrival intensity is given by $\lambda=Z^{2}$. Moreover, both $Z$ and $Y$ follow Ornstein-Uhlenbeck processes, with long-run means of $\mu_{Y} / \kappa_{Y}$ and $\mu_{Z} / \kappa_{Z}$, mean-reversion speeds of $\kappa_{Y}$ and $\kappa_{Z}$, and volatilities given by $\sigma_{Y}$ and $\sigma_{Z}$ respectively. ${ }^{11} Q$ is the percentage jump size, which is assumed to follow an independent log-normal distribution. The drift on the stock market index is adjusted for the average jump size with the term $\lambda \mu_{Q}$, and $\phi$ is the risk premium on the stock market index. $W_{S}, W_{Y}$, and $W_{Z}$ are Brownian motions and they are allowed to be interdependent according to a constant correlation matrix $\Sigma$.

Santa-Clara and Yan (2010) show that, for a representative investor who has wealth $W$ and allocates it entirely to the stock market, the risk premium $\phi$ can be expressed as a function of $Y$ and $Z$. Under this risk-adjusted probability measure, the inverse Fourier transformation of a function of the state variables is used to obtain the price $P=f(S, Y, Z ; K, T)$ of a European call option with strike price $K$ and maturity date $T$ (e.g. Lewis, 2000).

\footnotetext{
${ }^{11}$ Applying Ito's lemma, one can find the processes for $\nu$ and $\lambda$. The drift and covariance terms will not be linear in the state variables, making it a linear-quadratic jump-diffusion model.
} 
We apply Santa-Clara and Yan (2010) quasi-maximum likelihood approach ${ }^{12}$ and estimate the model for each country every week, using data for the stock index and four put option contracts $\left\{S_{t}, P_{t}^{1}, P_{t}^{2}, P_{t}^{3}, P_{t}^{4}\right\} .{ }^{13} P_{t}^{1}$ and $P_{t}^{2}$ are assumed to be observed without error and used to imply the state variables $Y_{t}$ and $Z_{t}$. Given the state variables, we calculate the model-based option prices for the other two option contracts and use them to compute the corresponding Black-Scholes implied volatilities. We also compute the Black-Scholes implied volatilities based on the observed market prices $P_{t}^{3}$ and $P_{t}^{4}$. Therefore $P_{t}^{3}$ and $P_{t}^{4}$ are used to calculate the measurement errors, defined as the difference between the model-based and the market-based implied volatilties. Table II reports summary statistics for the implied time series of diffusive volatility $\sqrt{\nu}$ and jump intensity $\lambda$, for the two funding currencies, Australia, and the US.

\section{[Table II here]}

Our US estimates are consistent with those obtained by Santa-Clara and Yan (2010), but we do find higher average volatility most likely due to the financial crisis period. Moreover, although volatility and jump intensity are correlated within and across countries, they still display different behavior over time, as illustrated by Figure 3.

[Figure 3 here]

\footnotetext{
${ }^{12}$ The estimation approach is described in detail in their paper, so we omit the details here. We also thank the authors for kindly making their estimation code available.

${ }^{13} P_{t}^{1}$ and $P_{t}^{2}$ have the shortest maturity (greater than 15 days and as close as possible to 30 days), $P_{t}^{3}$ and $P_{t}^{4}$ have the second shortest maturity (greater than 45 days and as close as possible to 60 days). $P_{t}^{1}$ and $P_{t}^{3}$ are closest to at-the-money, while $P_{t}^{2}$ and $P_{t}^{4}$ are closest to moneyness of 1.05.
} 


\section{Empirical Findings}

We now turn to testing the five hypotheses regarding the relation between funding risk, exchange rates, and speculators' activity. Given the importance of Japanese financial conditions to carry trade funding liquidity discussed above, we use the volatility and jump intensity estimated from stock options in Japan as our measures of funding risk. As the next sections will show, these measures perform striking well in explaining currency dynamics, speculators' activity, and carry trade returns. Moreover they outperform common measures of funding risk used in the literature, such as the TED spread. They also prove robust to the inclusion of a simple index of financial sector equity performance in Japan. Finally, very similar results are obtained with the measures calculated from stock options in Switzerland, therefore confirming the important role of the low-yield currencies. ${ }^{14}$

\section{A. Explaining FX Volatility and Correlations with Funding Risk}

Hypotheses 1 and 2 in Section I.C predict that increased funding risk leads to higher variability in both funding and investing currencies, as well as to a lower correlation between carry-short and carry-long currencies.

To test Hypothesis 1, we use a monthly measure of exchange rate volatility. For each currency, we calculate the standard deviation of daily currency returns (i.e. the symmetric of daily exchange rate changes against the USD) over the last month. The monthly measure of currency volatility, denoted by $F X^{\sigma}$, is calculated as the average of the individual standard deviations. We then regress the average volatility, $F X^{\sigma}$, on the funding risk in Japan, measured as the (monthly average) of the volatility and jump likelihood. ${ }^{15}$ To adjust

\footnotetext{
${ }^{14}$ The unreported results for Switzerland are available upon request.

${ }^{15}$ We also tried two alternative specifications: (i) using daily data on exchange rates, we calculated volatility over the previous week and then performed weekly regressions of $F X^{\sigma}$ on funding risk; (ii) again using daily
} 
for heteroskedasticity and serial correlation in the monthly regression residuals, we report Newey-West standard errors. Table III presents the results. The estimated coefficients are positive, confirming that currency volatility is increasing in funding risk.

\section{[Table III here]}

As Table III shows, the volatility and crash risk in the Japanese stock market alone explain, on average, a staggering $64 \%$ of monthly currency volatility. Table III also includes alternative measures of funding risk commonly used in the literature. In particular we consider the TED spread (measured as the difference between the 3-months LIBOR dollar rate and the 3-months T-Bill rate) and we find that it performs significantly worse than the Japanese crash risk. As a robustness test, and motivated by the empirical evidence discussed in subsection B.1, we also include the Japanese financial sector stock index in the regression. The financial sector equity prices in Japan can explain $15 \%$ of the currency volatility and they remain statistically significant in all regression specifications. Hypothesis 1 is therefore validated in the data.

Hypothesis 2 is also confirmed by our empirical results. In order to show it, we calculate the correlation coefficient between our investing (or 'long') currency, Australian dollar, and our funding (or 'short') currency, Japanese yen. As above, the correlation is calculated monthly (using daily data over the previous month) and we then regress it on our monthly average measures of funding risk. As can be seen from Table IV, the estimated coefficient for crash risk is negative and the corresponding adjusted $R^{2}$ is $23 \%$, confirming our hypothesis that the correlation between investing and funding currencies decreases when funding conditions tighten.

data, we calculated volatility over the previous month, and then performed rolling weekly regressions. All three alternatives deliver similar conclusions, but the specification shown is preferred as it is less noisy than (i) and avoids potential issues with the overlapping data used in (ii). 
[Table IV here]

\section{B. Explaining Currency Crashes and Skewness with Funding Risk}

The cross-sectional differences in currency skewness are well-known in the literature. Consistent with previous work, we also find that average skewness is positive and highest for Japanese yen (the main carry trade funding currency), while negative and lowest for Australian and New Zealand dollars (the main carry trade investing currencies).

In our model, if the funding constraints do not bind, the currency variability is smaller. When funding constraints start binding, there is potentially first a currency crash in both the funding and investment currencies. Any further tightening of funding constraints, in turn, leads to further depreciation of the investment currencies but an appreciation of the funding currencies. Given these effects, our model predicts that the currency returns are negatively skewed for the investment currencies, but not necessarily so for the funding currencies. Therefore, let us investigate if countries' different exposures to funding risk help to explain the cross-sectional differences in exchange rate skewness. Following Brunnermeier et al. (2009), we calculate realized skewness from daily exchange rate returns within (overlapping) quarterly time periods, and then take the time-series average. We measure the countries' exposure to funding risk by the estimated coefficient of regressing individual monthly currency returns on monthly average Japanese crash risk, $\lambda$.

Figure 4 shows a clear positive relationship between countries' exposures to funding risk and currency skewness, i.e. returns to currencies with large negative coefficients for $\lambda$ (such as Australia or New Zealand dollars) are negatively skewed. The relationship between high interest rate differentials and negative skewness, observed in Brunnermeier et al. (2009), is therefore associated with heterogeneous country exposures to funding risk. The result 
supports the prediction that the stock market risks in funding currency countries are a significant factor in explaining the negative skewness of investment currency returns.

[Figure 4 here]

In addition, our model predicts that a strong tightening of credit conditions is associated with crashes of the investment currencies and large appreciations of the funding currencies. To test these predictions in the data, we estimate a probit model where the dependent variable is the likelihood of a crash in carry trade portfolio returns. We start by constructing a carry portfolio, that holds a long-carry currency (AUD) and shorts a low-yield currency (JPY), and we calculate its return against a basket of six non carry-currencies during that

month. The dependent variable takes value 1 if there is a crash in this portfolio (defined as a negative return lower than minus one standard deviation on a given month) and 0 otherwise. The results are presented in Table $\mathrm{V}$, where we show that increases in funding crash risk $\lambda$ indeed lead to a higher likelihood of currency crashes. As before, we also present the results for the TED spread with very similar conclusions. Therefore Hypothesis 3 is confirmed empirically.

[Table $\mathrm{V}$ here]

\section{Explaining Speculative Activity and Carry Trade Returns with Funding Risk}

\section{C.1. Speculators' Trading Activity}

We now turn to the effect of funding risk on trading activity in the currency market. We follow Brunnermeier et al. (2009) and use the futures position data from the CFTC as a 
proxy for carry trade activity, measured at weekly frequency. In particular, we look at the net (long minus short) futures position of noncommercial traders in the foreign currency, expressed as a percentage of total open interest of all traders. ${ }^{16}$ Noncommercial traders represent the investors that use futures for speculative purposes.

Table VI shows the results from regressing speculative activity on funding risk, for both individual currencies involved in carry trades and for the long-short position (long AUD/short JPY).

\section{[Table VI here]}

Funding risk measures from Japan are able to explain $28 \%$ of the long-short positions in AUD/JPY (the TED spread can explain 18\%). Furthermore, we obtain negative coefficients for the funding risk when explaining the long-short flows, i.e. a worsening of borrowing conditions causes unwinding of carry trades. Consistent findings are obtained for the futures positions held in individual currencies - an increase in funding risk causes a decrease in investment-currency positions and an increase in funding-currency positions (i.e. a reduction of shorting). Moreover, and as predicted by condition (13), funding risk has greater impact on carry-long currencies than on carry-short currencies. Therefore Hypothesis 4 is empirically verified.

\section{C.2. Carry Trade Returns}

We now turn to the effect of funding risk on currency carry trade returns. We follow the common procedure in the literature and decompose the effect of both the diffusive volatility and the crash likelihood into expected and unexpected components. An analysis of the

\footnotetext{
${ }^{16} \mathrm{~A}$ positive futures position is equivalent to a currency trade in which the foreign currency is the investment currency and the USD is the funding currency.
} 
partial autocorrelations of each weekly time series shows that they are best modeled with three autoregression lags, as the shocks extracted in this way seem to be serially uncorrelated. In particular, we fit an $A R(3)$ model to each one of the implied state variables $\sqrt{\nu}$ and $\lambda$. The expected market risks are the fitted values of the estimation, and we denote them by $\sqrt{\nu}^{e}$ and $\lambda^{e}$; the residuals, denoted by $\sqrt{\nu}^{u}$ and $\lambda^{u}$, are used as our estimation of the unexpected innovations. ${ }^{17}$

If the abnormal returns to carry trades increase in funding risk as the model predicts, then higher expected market risk at time $t, \sqrt{\nu}^{e}$ and $\lambda^{e}$, should lead to higher expected carry trade returns, while the effect of positive unexpected shocks (residuals), i.e. positive $\sqrt{\nu}^{u}$ and $\lambda^{u}$, should be associated with negative contemporaneous returns. To confirm this conjecture, we regress monthly carry trade returns on the monthly averages of expected funding risk and residuals. We also include lagged residuals of crash risk in our regressions as, due to the slow moving capital (e.g. see Duffie, 2010), the market reaction may be slow (lagged residuals of volatility are not statistically significant and therefore are omitted). As expected, we obtain positive coefficients on the fitted values and negative estimates for the residuals. Table VII presents the results for the different carry trade portfolios, using stock market related risks in Japan.

\section{[Table VII here]}

Noting the very high $R^{2}$ 's of the regressions, it is clear that funding risk in carry-short countries has a remarkably high explanatory power for carry trade returns, thus validating Hypothesis $5 .{ }^{18}$ Moreover, we note that the funding-country equity market risks have a

\footnotetext{
${ }^{17}$ The residuals behave quite differently in the cross-section. For example, the correlations between the 'unexpected crash risks' vary from a minimum of $-1.18 \%$ (non-significant correlation between US and Japan) to a maximum of $29.7 \%$ (between US and Switzerland).

${ }^{18}$ As a robustness check, Table A.2 in Appendix shows the same results for the Switzerland funding risk measures.
} 
more important effect than the same factors calculated from the US market. ${ }^{19}$ For instance, the $R^{2}$ of the regression of $H m L$ returns on US equity market volatility and crash risk is below $24 \%$, substantially lower than the fit of $36 \%$ found for the case of Japan. This point is further stressed in Table VIII, where we include both Japanese and US measures. First, the predictive power of funding risk for carry trade returns is stronger for the case of Japan. Second, in a full regression, only the Japanese measures remain statistically significant. Both conclusions also hold when considering Switzerland as the funding country.

Overall the inclusion of other measures of funding risk, such as the TED spread or VIX, does not affect the statistical significance of the stock market risks in the funding currencies. ${ }^{20}$ Very similar conclusions, confirming the robustness of the results, are obtained if we include in our regression other variables, such as the US stock returns, the Japanese financial sector index, or the innovations in global FX volatility (as in Menkhoff et al., 2012).

\section{[Table VIII here]}

\section{Conclusion}

In this paper we develop a new measure of funding risk, allowing us to confirm the importance of funding constraints in currency speculation, therefore extending the results in Brunnermeier, Nagel, and Pedersen (2009). We measure funding risk for carry trades using the equity options' implied stock market volatility and crash risk in Japan, the most typical carry trade funding country. This measure seems to be a good proxy for speculators' ability

\footnotetext{
${ }^{19}$ During the period under study, the US interest rate levels are both below the median level (in the early 2000's and after 2008) as well as above the median level (between late 2004 and 2008). Therefore the role of the US dollar as either a funding or investing currency has changed over time.

${ }^{20} \mathrm{~A}$ decomposition of carry trade returns on interest rate and currency effects (not presented here) shows that the TED spread seems to have a much greater relation to the interest rate component, while funding risk is more important to explain the currency effect.
} 
in obtaining funds for carry trading, as it has a remarkably strong explanatory power for currency carry trade returns and speculators' trading activity. We develop a stylized model that is consistent with our empirical findings.

\section{References}

[1] Adrian, Tobias, Erkko Etula, and Tyler Muir, 2013, Financial Intermediaries and the Cross-Section of Asset Returns, The Journal of Finance (forthcoming).

[2] Adrian, Tobias, and Hyun Song Shin, 2010, Liquidity and Leverage, Journal of Financial Intermediation 19, 418-437.

[3] Barroso, Pedro, and Pedro Santa-Clara, 2012, Beyond the Carry Trade: Optimal Currency Portfolios, working paper.

[4] Bekaert, Geert, The Time-variation of Expected Returns and Volatility in Foreignexchange Markets: A General Equilibrium Perspective, The Review of Financial Studies $9,427-470$.

[5] Brunnermeier, Markus, Stefan Nagel, and Lasse H. Pedersen, 2009, Carry Trades and Currency Crashes, NBER Macroeconomics Annual 2008, Volume 23, Cambridge, MA, $313-347$.

[6] Brunnermeier, Markus, and Lasse H. Pedersen, 2009, Market Liquidity and Funding Liquidity, The Review of Financial Studies 22 (6), 2201-2238.

[7] Burnside, Craig, Martin Eichenbaum, Isaac Kleshchelski, Sergio Rebelo, 2011, Do Peso Problems Explain the Returns to the Carry Trade?, The Review of Financial Studies 
$24(3), 853-891$.

[8] Duffie, Darrell, 2010, Presidential Address: Asset Price Dynamics with Slow-moving Capital, The Journal of Finance 65 (4), 1237-1267.

[9] Fama, Eugene, and Andre Farber, 1979, Money, bonds, and foreign exchange, The American Economic Review 69, 639-649.

[10] Galati, Gabriele, Alexandra Heath, and Patrick McGuire, 2007, Evidence of Carry Trade Activity, BIS Quarterly Review, September 2007.

[11] Gromb, Denis, and Dimitri Vayanos, 2002, Equilibrium and welfare in markets with financially constrained arbitrageurs, Journal of Financial Economics 66, 361-407.

[12] Hau, Harald and Hélène Rey, 2006, Exchange Rate, Equity Prices and Capital Flows, Review of Financial Studies 19, 273-317.

[13] Hattori, Masazumi, and Hyun Song Shin, 2009, Yen Carry Trade and the Subprime Crisis, IMF Staff Papers 56 (2), 384-409.

[14] Ichiue, Hibiki, and Kentaro Koyama, 2011, Regime switches in exchange rate volatility and uncovered interest parity, Journal of International Money and Finance 30, 14361450.

[15] Jylhä, Petri, and Matti Suominen, 2011, Speculative capital and currency carry trades, Journal of Financial Economics 99, 60-75.

[16] Jurek, Jakub W., 2009, Crash-neutral Currency Carry Trades, working paper.

[17] Korajczyk, Robert, and Claude Viallet, 1992, Equity Risk Premia and the Pricing of Foreign Exchange Risk, Journal of International Economics. 33 (3-4), 199-219. 
[18] Lettau, Martin, Matteo Maggiori, and Michael Weber, 2013, Conditional Risk Premia in Currency Markets and Other Asset Classes, Journal of Financial Economics, forthcoming.

[19] Lewis, Alan, 2000, Option valuation under stochastic volatility, Newport Beach, CA: Finance Press.

[20] Lustig, Hanno, Nikolai Roussanov, and Adrien Verdelhan, 2011, Common risk factors in currency markets, The Review of Financials Studies 24 (11), 3731-3777.

[21] McGuire, Patrick, and Goetz von Peter, 2009, The US dollar shortage in global banking, BIS Quarterly Review, March 2009.

[22] Menkhoff, Lukas, Lucio Sarno, Maik Schmeling and Andreas Schrimpf, 2012, Carry Trades and Global Foregin Exchange Volatility, The Journal of Finance 67 (2), 681-718.

[23] Santa-Clara, Pedro, and Shu Yan, 2010, Crashes, Volatility, and the Equity Premium: Lessons from S\&P500 Options, The Review of Economics and Statistics 92 (2), 435-451.

[24] Shleifer, Andrei, and Robert Vishny, 1997, The Limits of Arbitrage, The Journal of Finance, 52 (1), 35-55. 

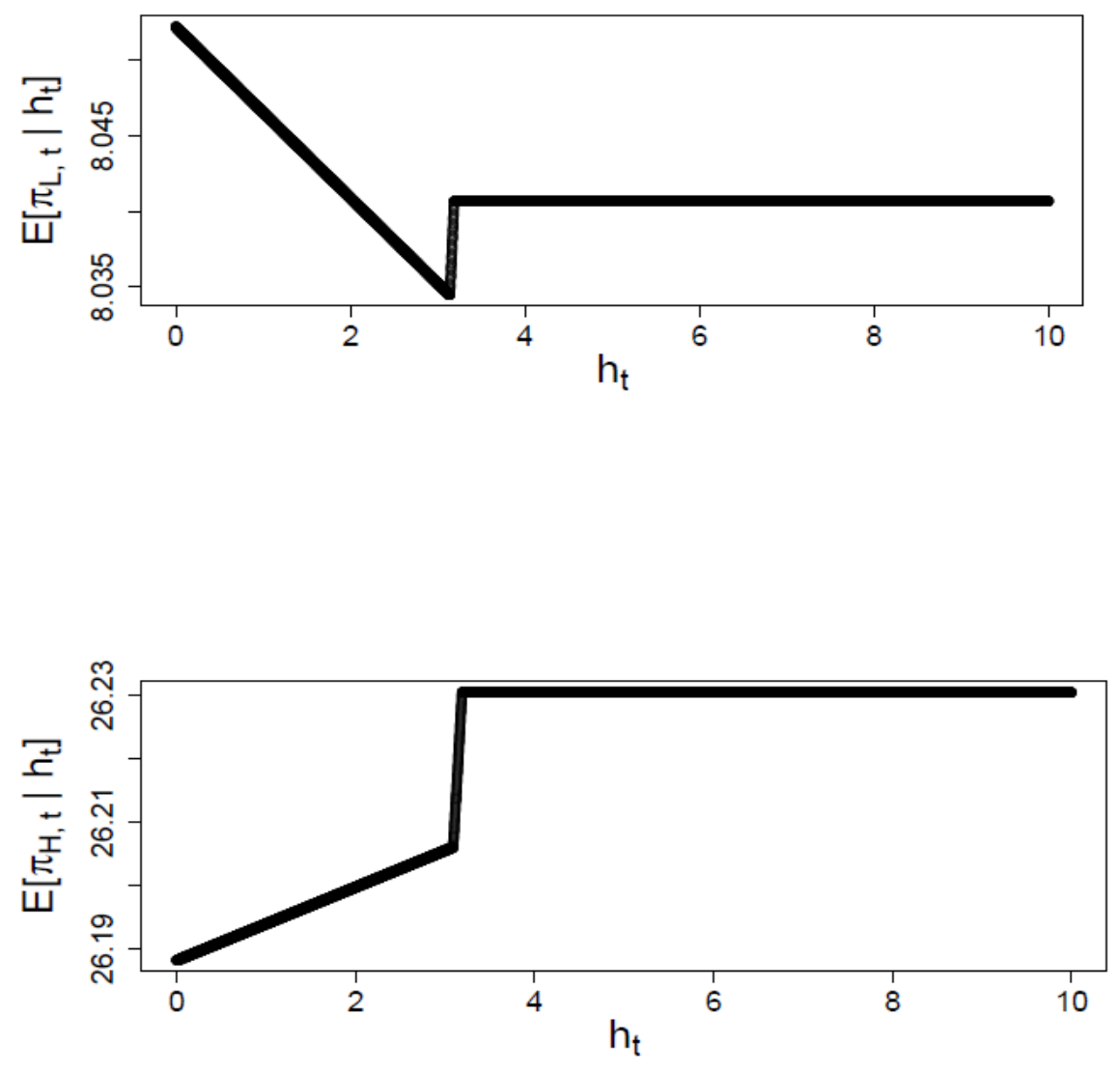

Figure 1. The Effect of Funding Conditions on Exchange Rates (PRELIMINARY RESULTS). This Figure shows the dynamics of the purchasing power for each country, as a function of the funding conditions, $h_{L}$. The first plot shows the case for the funding currency (Country $L$ ), while the second plot shows the case for the investment currency (Country $H$ ). 


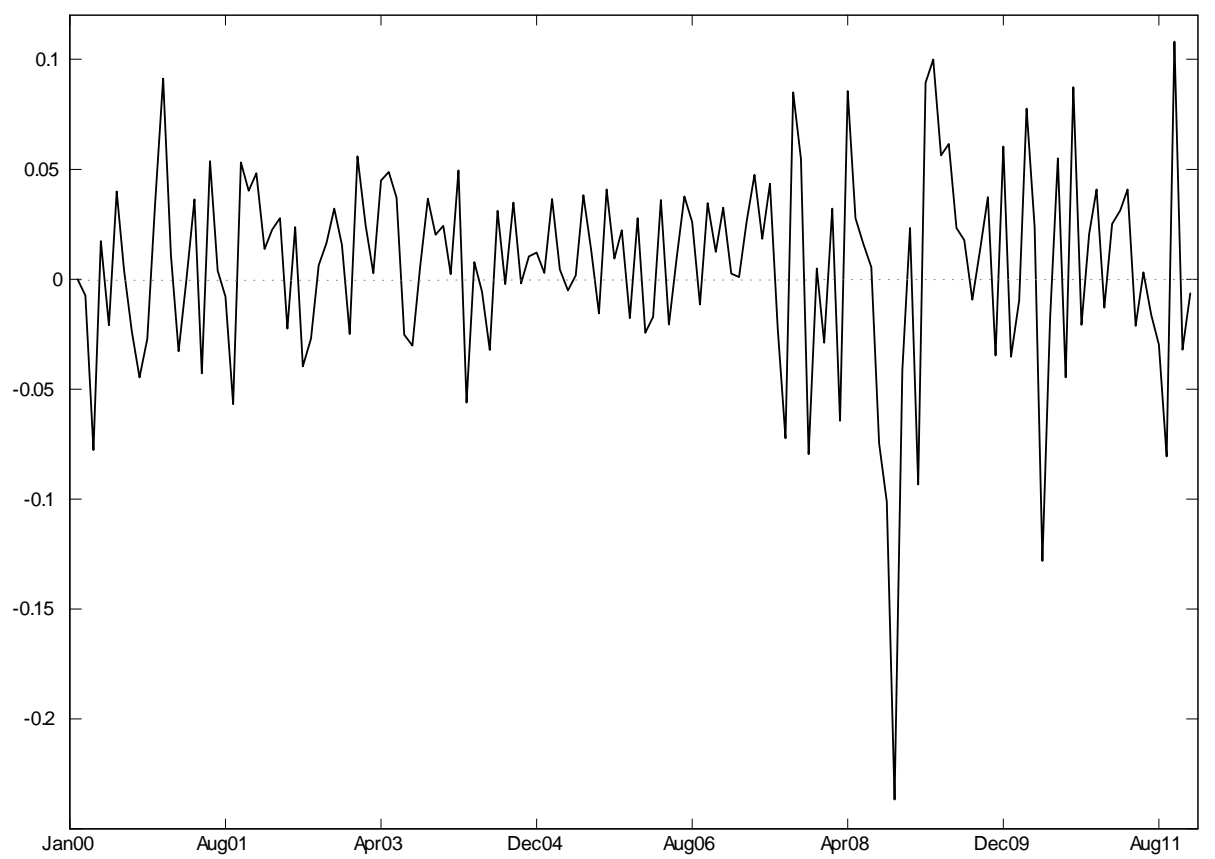

Figure 2. Monthly Carry Trade Returns for the AUmJP Strategy. This Figure shows the monthly returns of the $A U m J P$ carry trade strategy, which corresponds to an investment strategy where investors borrow in Japanese yen and invest in Australian dollar. Results are presented for the period covering January 2000 to December 2011. 

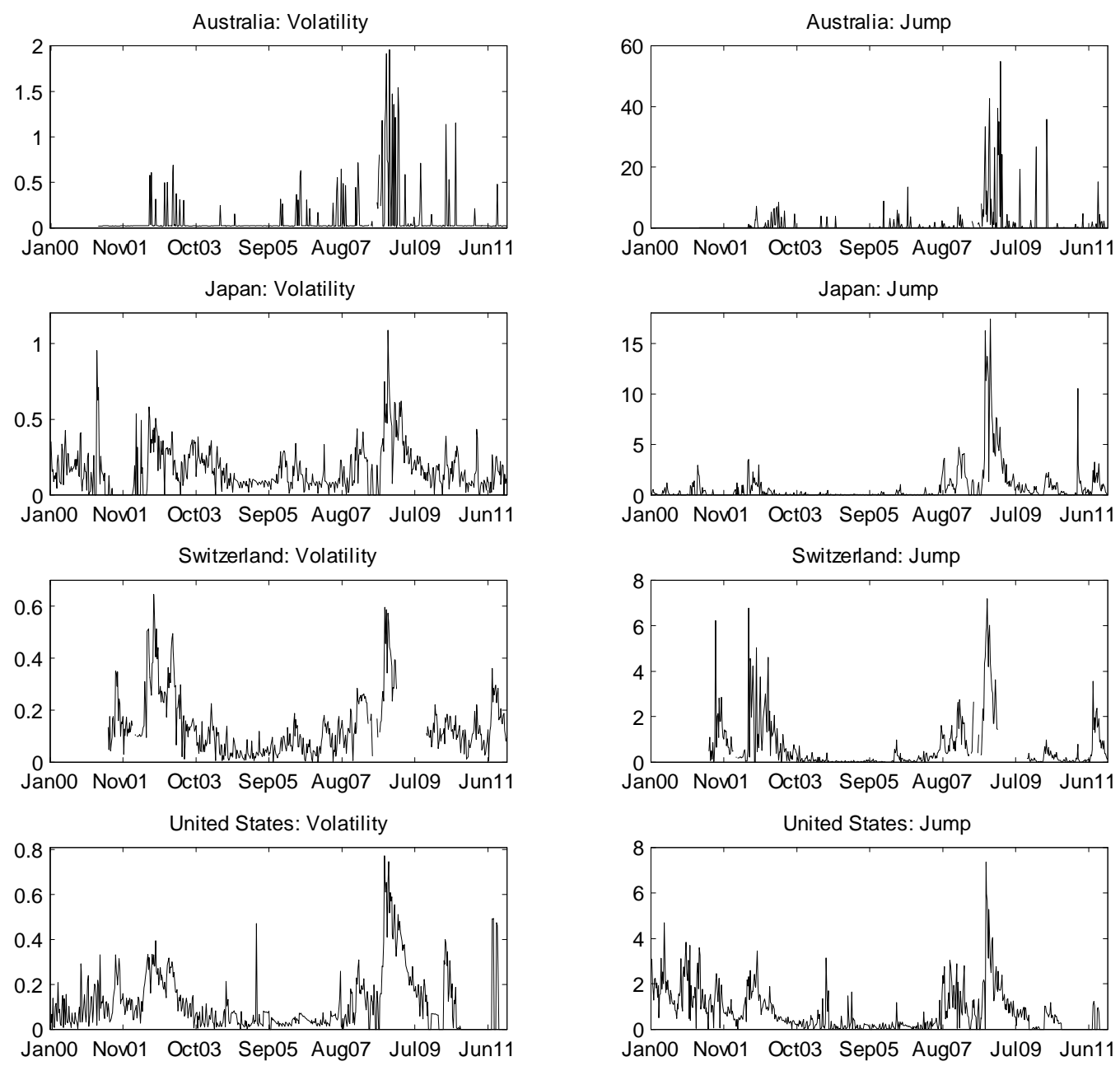

Figure 3. Volatility and Jumps. This Figure shows the estimated time series of the diffusive volatility (left column) and jump intensity (right column) for each market. Both risk measures are estimated from option data on stock market indices. The time period covered is January 2000 to December 2011. The data for Australia and Switzerland start in 2001. 


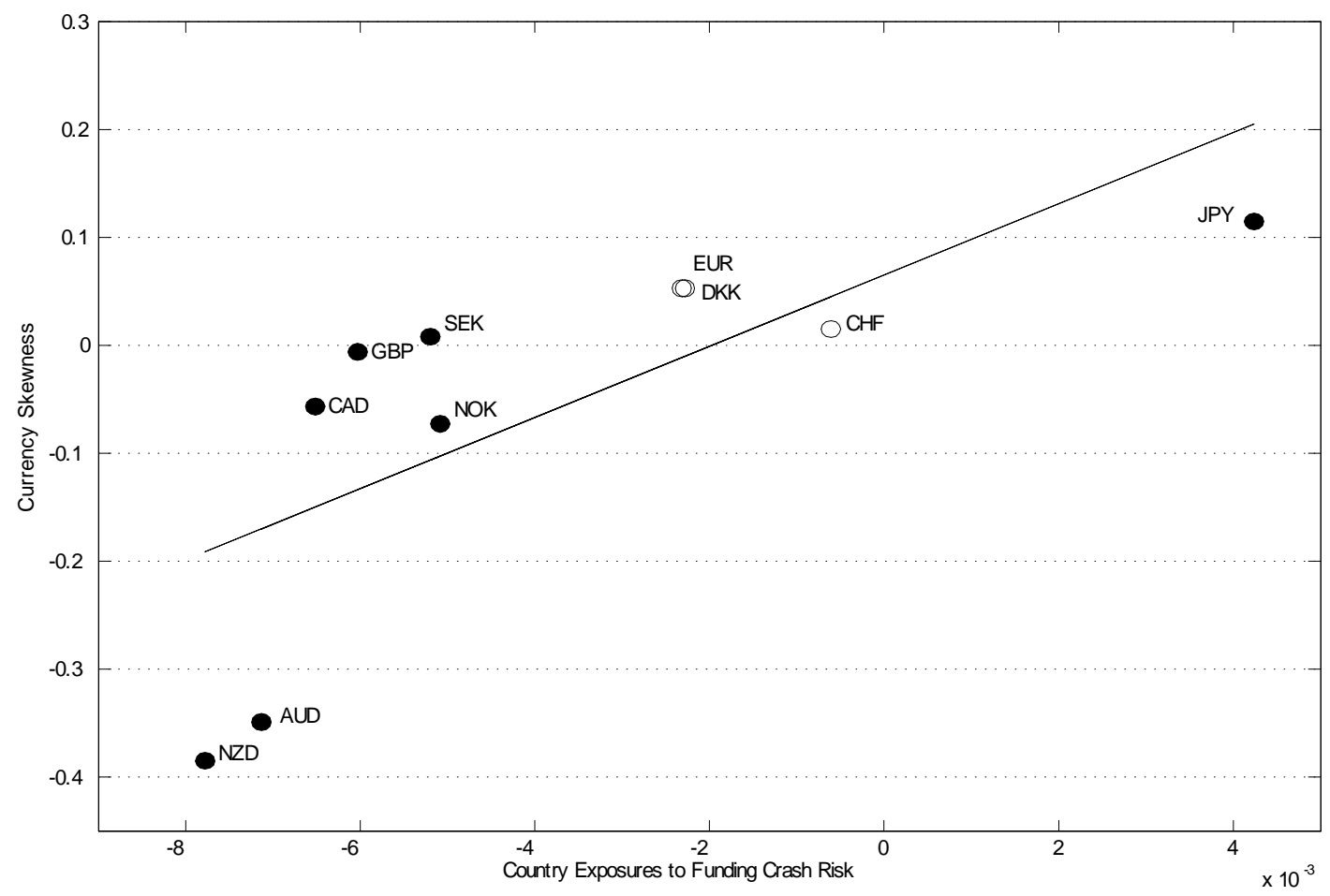

Figure 4. Skewness and Funding Risk. This Figure shows the positive relationship between the country exposures to funding risk and average currency skewness. The exposures to funding risk are the estimated coefficient from a regression of individual monthly currency returns on the monthly average Japanese crash risk. All the coefficients in these individual regressions are statistically significant at one percent level, with the exception of CHF, DKK, and EUR (corresponding to the unfilled markers). For the currency skewness, we use daily exchange rate returns within (overlapping) quarterly time periods, and then take the time-series average. The line shows the fitted values of regressing currency skewness on country exposures, and the corresponding fit is $51 \%$. 


\section{Table I \\ Monthly Carry Trade Returns: Summary Statistics}

This table shows the summary statistics of the monthly returns on the different carry trade strategies. It includes the mean, standard deviation, skewness, kurtosis and median. The total number of observations is 144 months. Numbers in parentheses show the standard error of the mean returns.

\begin{tabular}{lccccc}
\hline Strategy & Mean & Std. Dev. & Skewness & Kurtosis & Median \\
\hline HmL & 0.0070 & 0.0416 & -1.3407 & 7.3109 & 0.0111 \\
& $(0.0035)$ & & & & \\
AUmJP & 0.0059 & 0.0459 & -1.2298 & 7.8532 & 0.0103 \\
& $(0.0038)$ & & & & \\
HmL3 & 0.0040 & 0.0244 & -0.8174 & 5.3299 & 0.0065 \\
& $(0.0020)$ & & & & 0.0041 \\
HmL5 & 0.0022 & 0.0173 & -0.8826 & 5.7698 & \\
\hline
\end{tabular}


Table II

\section{Our Measures of Funding Risk: Volatility and Crash Risk}

This table shows the summary statistics of the implied state variables, i.e. the diffusive volatility $\sqrt{\nu}$ and the jump intensity $\lambda$. Both variables are estimated using option data from the stock markets. It includes the mean, standard deviation, skewness, kurtosis, autocorrelation and the correlation between volatility and crash risk for each case. Results are presented for the main carry-investing country, Australia, for the main carry-funding countries, Japan and Switzerland, as well as for the benchmark market, US.

\begin{tabular}{llcccccc}
\hline Countries & & Mean & Std.Dev. & Skewness & Kurtosis & Autocorr. & Corr $(\sqrt{v}, \lambda)$ \\
\hline \multirow{2}{*}{ Australia } & $\sqrt{\nu}$ & 0.09 & 0.24 & 4.64 & 27.44 & 0.32 & 0.30 \\
& $\lambda$ & 1.29 & 5.21 & 6.24 & 47.19 & 0.27 & \\
\multirow{2}{*}{ Japan } & $\sqrt{\nu}$ & 0.18 & 0.14 & 1.87 & 8.83 & 0.71 & 0.54 \\
& $\lambda$ & 0.83 & 1.93 & 4.83 & 31.53 & 0.80 & \\
\multirow{2}{*}{ Switzerland } & $\sqrt{\nu}$ & 0.14 & 0.12 & 1.66 & 6.01 & 0.85 & 0.68 \\
& $\lambda$ & 0.66 & 1.12 & 2.89 & 12.54 & 0.72 & \\
& & & & & & & \\
United States & $\sqrt{\nu}$ & 0.13 & 0.13 & 1.85 & 6.94 & 0.84 & 0.50 \\
& $\lambda$ & 0.89 & 0.96 & 2.09 & 9.88 & 0.70 & \\
\hline
\end{tabular}




\section{Table III}

\section{Exchange Rate Volatility and Funding Risk}

This table shows the explanatory power of funding risk in Japan for the average monthly currency standard deviation, denoted by $F X^{\sigma}$. For each currency in the sample of ten developed countries, the volatility is calculated monthly using the daily exchange rate changes against USD. $\nu$ and $\lambda$ are the monthly average volatility and jump likelihood, computed from stock option data in Japan. Model (1) shows that the funding risk measures in Japan alone, in particular crash risk, are able to explain $46 \%$ of FX volatility. Models (2) and (3) show that alternative measures of funding risk, such as the TED spread or the Japanese financial index (JP Fin.), perform significantly worse in explaining currency volatility. Model (4) shows the regression results when including all measures. JP Fin. is obtained from Datastream and divided by 100 for expositional purpose. For each estimated coefficient, the corresponding t-statistics are computed using Newey-West standard errors (with a lag of five months). ${ }^{* *}\left(^{*}\right)$ shows statistical significance at 1 (5) percent. The numbers in brakets show the mean Variance Inflation Factor (VIF), where values of VIF smaller than 10 as shown indicate absence of multicollinearity issues.

\begin{tabular}{|c|c|c|c|c|c|c|c|c|}
\hline \multirow[t]{2}{*}{$F X^{\sigma}$} & \multicolumn{2}{|c|}{ (1) } & \multicolumn{2}{|c|}{$(2)$} & \multicolumn{2}{|c|}{$(3)$} & \multicolumn{2}{|c|}{$(4)$} \\
\hline & Coef. & t-stat & Coef. & t-stat & Coef. & t-stat & Coef. & t-stat \\
\hline$\lambda^{J P}$ & $0.0011^{* *}$ & 9.99 & - & & - & & $0.0009^{* *}$ & 7.71 \\
\hline$\sqrt{\nu}^{J P}$ & 0.0017 & 0.78 & - & & 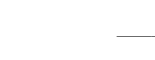 & & 0.0012 & 0.57 \\
\hline JP Fin. & 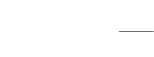 & & $-0.0007^{* *}$ & -2.87 & 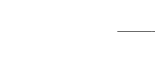 & & $-0.0004^{* *}$ & -3.21 \\
\hline TED & - & & - & & $0.0021^{*}$ & 2.04 & 0.0005 & 1.10 \\
\hline const. & $0.0056^{* *}$ & 17.48 & $0.0092^{* *}$ & 7.77 & $0.0056^{* *}$ & 12.59 & $0.0070^{* *}$ & 14.93 \\
\hline $\operatorname{Adj} . R^{2}$ & 64.4 & & 15. & & 22.8 & & 67.7 & \\
\hline VIF & {$[1$.} & & & & & & {$[2$.} & \\
\hline
\end{tabular}




\section{Table IV \\ Exchange Rate Correlations and Funding Risk}

This table shows the explanatory power of crash risk for the correlation coefficient between the main long currency (Australian Dollar) and the main short currency (Japanese Yen). The correlation coefficient is calculated monthly, using the daily exchange rate changes against USD. $\nu$ and $\lambda$ are the monthly average volatility and jump likelihood, computed from stock option data in the Japanese market. Model (1) shows that the funding risk measures in Japan alone, in particular crash risk, are able to explain $23 \%$ of currency correlation. Models (2) and (3) show the results for alternative measures of funding risk, the Japanese financial index (JP Fin.) and the commonly used TED spread. The Japanese financial sector index is obtained from Datastream and divided by 100 for expositional purpose. Model (4) shows the regression results when including all measures. The t-statistics shown in the second column are computed using NeweyWest standard errors (with a lag of five months). ${ }^{* *}(*)$ shows statistical significance at 1 (5) percent.

\begin{tabular}{|c|c|c|c|c|c|c|c|c|}
\hline \multirow[t]{2}{*}{$\mathrm{AU} / \mathrm{JP}$} & \multicolumn{2}{|c|}{ (1) } & \multicolumn{2}{|c|}{$(2)$} & \multicolumn{2}{|c|}{ (3) } & \multicolumn{2}{|c|}{ (4) } \\
\hline & Coef. & t-stat & Coef. & t-stat & Coef. & t-stat & Coef. & t-stat \\
\hline$\lambda^{J P}$ & $-0.1300^{* *}$ & -3.58 & - & - & - & & $-0.0673^{*}$ & -2.16 \\
\hline$\sqrt{\nu}^{J P}$ & 0.0384 & 0.10 & & - & - & - & 0.0432 & 0.13 \\
\hline JP Fin. & - & & 0.0501 & 1.25 & - & & 0.0507 & 1.92 \\
\hline TED & - & & & - & $-0.3542^{* *}$ & -5.07 & $-0.2577^{* *}$ & -3.26 \\
\hline const. & $0.2885^{* *}$ & 3.16 & 0.0162 & 0.11 & $0.3893^{* *}$ & 5.41 & 0.2056 & 1.90 \\
\hline $\operatorname{Adj} . R^{2}$ & 23 . & & & & 20 . & & 28. & \\
\hline
\end{tabular}




\section{Table V \\ Currency Crashes and Funding Risk}

This table shows the explanatory power of funding risk for currency crashes. We estimate a probit model, where the dependent variable takes value 1 if there is a crash in the currency carry portfolio, and 0 otherwise. The 'carry portfolio' consists on holding a long-carry currency (AUD) and shorting a low-yield currency (JPY), and we calculate its return against a basket of six currencies (which does not include the investment or the funding currencies) during that month. We define a crash when the portfolio return is lower than (minus) 1 standard deviation of its returns during the whole sample period. In Model (1), we show that changes in funding risk estimated from Japanese stock options data $(\Delta \lambda)$, both contemporaneous and lagged, can explain $27 \%$ of currency crashes. Model (2) considers the same type of regression for the TED spread. Model (3) shows the result when including only contemporaneous changes and Model (4) considers all variables. Contemporaneous and lagged changes of the Japanese financial sector index or stochastic volatility are not statistically significant, so they are excluded here. The z-statistics are computed using robust standard errors and $*^{*}(*)$ shows statistical significance at $1(5)$ percent. The last row shows pseudo- $R^{2} s$.

\begin{tabular}{|c|c|c|c|c|c|c|c|c|}
\hline & \multicolumn{2}{|c|}{ (1) } & \multicolumn{2}{|c|}{ (2) } & \multicolumn{2}{|c|}{ (3) } & \multicolumn{2}{|c|}{ (4) } \\
\hline & Coef. & z-stat & Coef. & z-stat & Coef. & z-stat & Coef. & z-stat \\
\hline \multicolumn{9}{|l|}{$\Delta \lambda^{J P}$} \\
\hline L0. & $0.9148^{* *}$ & 2.63 & - & - & $0.6522^{*}$ & 2.08 & $1.9317^{* *}$ & 3.48 \\
\hline L1. & 0.1834 & 1.68 & 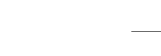 & - & 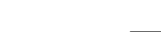 & & $1.0221^{*}$ & 2.49 \\
\hline $\mathrm{L} 2$. & $0.3421^{* *}$ & 2.56 & - & & - & & $1.4137^{* *}$ & 2.97 \\
\hline L3. & $0.6614^{*}$ & 2.29 & - & & - & & $1.8674^{* *}$ & 4.16 \\
\hline \multicolumn{9}{|l|}{$\triangle T E D$} \\
\hline L0. & 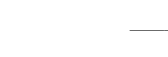 & & $2.3471^{*}$ & 2.50 & $1.5774^{*}$ & 2.40 & 3.3636 & 1.82 \\
\hline L1. & 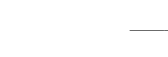 & & $1.7988^{* *}$ & 3.12 & - & & 0.1328 & 0.14 \\
\hline $\mathrm{L} 2$. & 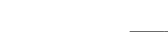 & & 0.6304 & 1.63 & - & & $-3.4263^{*}$ & -2.05 \\
\hline L3. & 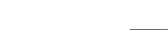 & & 0.3573 & 0.38 & - & & $-3.2563^{*}$ & -2.36 \\
\hline const. & $-1.5650^{* *}$ & -8.66 & $-1.4450^{* *}$ & -6.03 & $-1.5601^{* *}$ & -7.47 & $-2.1882^{* *}$ & -5.75 \\
\hline PseudoR ${ }^{2}$ & \multicolumn{2}{|c|}{$26.82 \%$} & \multicolumn{2}{|c|}{$29.52 \%$} & \multicolumn{2}{|c|}{$30.23 \%$} & \multicolumn{2}{|c|}{$54.12 \%$} \\
\hline
\end{tabular}




\section{Table VI Weekly Carry Trade Activity}

This table shows the explanatory power of funding risk for the weekly carry trade activity. The dependent variables are the net futures position in $A U D$ minus net futures position in $J P Y$, as well the positions in individual currencies $A U D, C H F$, and $J P Y$. As before, $\nu$ and $\lambda$ are the volatility and jump likelihood, computed from stock option data in Japan. In Panel A, Model (1) shows that the funding risk measures in Japan alone are able to explain $28 \%$ of the composite futures position. Models (2) and (3) show that alternative measures of funding risk, such as the Japanese financial index (JP Fin.) or the commonly used TED spread, perform significantly worse. Model (4) shows the regression results when including all measures. Panel B shows the explanatory power of funding risk in Japan for futures positions in individual currencies. The number of weeks considered is 626 . The t-statistics are computed using robust standard errors and $* *$ (*) shows statistical significance at 1 (5) percent.

Panel A: Futures AU-JP

\begin{tabular}{|c|c|c|c|c|c|c|c|c|}
\hline & \multicolumn{2}{|c|}{$(1)$} & \multicolumn{2}{|c|}{$(2)$} & \multicolumn{2}{|c|}{$(3)$} & \multicolumn{2}{|c|}{$(4)$} \\
\hline & Coef. & t-stat & Coef. & t-stat & Coef. & t-stat & Coef. & t-stat \\
\hline$\lambda^{J P}$ & $-0.0353^{* *}$ & -4.64 & - & & & & -0.0046 & -0.52 \\
\hline$\sqrt{\nu}^{J P}$ & $-0.9380^{* *}$ & -8.85 & - & & - & & $-0.7309^{* *}$ & -6.90 \\
\hline JP Fin. & 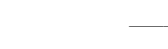 & & $0.0010^{* *}$ & 10.13 & - & & $0.0009^{* *}$ & 7.65 \\
\hline TED & 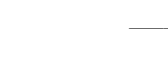 & & - & & $-0.1515^{* *}$ & -6.10 & $-0.1291^{* *}$ & -3.97 \\
\hline const. & $0.4861^{* *}$ & 21.31 & $-0.0938^{* *}$ & -2.58 & $0.3518^{* *}$ & 19.83 & $0.1825^{* *}$ & 4.31 \\
\hline Adj. $R^{2}$ & \multicolumn{2}{|c|}{$27.59 \%$} & \multicolumn{2}{|c|}{$17.53 \%$} & \multicolumn{2}{|c|}{$5.50 \%$} & \multicolumn{2}{|c|}{$36.45 \%$} \\
\hline
\end{tabular}

Panel B: Futures Positions in Individual Currencies

\begin{tabular}{|c|c|c|c|c|c|c|}
\hline & \multicolumn{2}{|c|}{ Futures AUD } & \multicolumn{2}{|c|}{ Futures CHF } & \multicolumn{2}{|c|}{ Futures JPY } \\
\hline & Coef. & t-stat & Coef. & t-stat & Coef. & t-stat \\
\hline$\lambda^{J P}$ & $-0.0128^{* *}$ & -2.82 & $-0.0145^{*}$ & -2.23 & $0.0251^{* *}$ & 4.22 \\
\hline$\sqrt{\nu}^{J P}$ & $-0.5371^{* *}$ & -8.10 & 0.1499 & 1.44 & $0.3605^{* *}$ & 4.31 \\
\hline const. & $0.3868^{* *}$ & 26.58 & $-0.0815^{* *}$ & -3.74 & $-0.1011^{* *}$ & -5.91 \\
\hline$A d j . R^{2}$ & \multicolumn{2}{|c|}{$14.80 \%$} & \multicolumn{2}{|c|}{$0.31 \%$} & \multicolumn{2}{|c|}{$11.59 \%$} \\
\hline
\end{tabular}




\section{Table VII}

\section{Explaining Monthly Carry Trade Returns with Funding Risk in Japan}

This table shows the results of regressing monthly carry trade returns on funding risk, calculated from option data on the Japanese stock market. $\nu^{e}$ and $\lambda^{e}$ are the monthly averages of fitted values for the volatility and jump likelihood. $\nu^{u}$ and $\lambda^{u}$ are the average residuals and correspond to the unexpected component of risk. Four portfolio strategies are shown, AUmJP, HmL, HmL3 and HmL5, with corresponding returns calculated for the period covering January 2000 to December 2011 (for a total of 144 observations). The t-statistics are computed using robust standard errors and $*^{*}(*)$ shows statistical significance at 1 (5) percent.

\begin{tabular}{|c|c|c|c|c|c|c|c|c|}
\hline \multirow[t]{2}{*}{ Strategy } & \multicolumn{2}{|c|}{ AUmJP } & \multicolumn{2}{|c|}{$\mathrm{HmL}$} & \multicolumn{2}{|c|}{ HmL3 } & \multicolumn{2}{|c|}{ HmL5 } \\
\hline & Coef. & t-stat & Coef. & t-stat & $\overline{\text { Coef. }}$ & t-stat & Coef. & t-stat \\
\hline$\lambda^{e}$ & $0.0168^{* *}$ & 2.95 & $0.0148^{*}$ & 2.40 & $0.0106^{* *}$ & 2.83 & $0.0050^{*}$ & 2.02 \\
\hline$\sqrt{\nu}^{e}$ & 0.0761 & 1.34 & -0.0121 & -0.23 & 0.0330 & 0.97 & 0.0164 & 0.67 \\
\hline \multicolumn{9}{|l|}{$\lambda^{u}$} \\
\hline L0. & $-0.0670 * *$ & -8.55 & $-0.0576^{* *}$ & -8.48 & $-0.0344^{* *}$ & -7.39 & $-0.0222^{* *}$ & -6.84 \\
\hline L1. & $-0.0214^{*}$ & -2.38 & $-0.0281^{* *}$ & -2.98 & $-0.0167^{* *}$ & -2.68 & -0.0058 & -1.55 \\
\hline $\mathrm{L} 2$. & $-0.0367 * *$ & -4.48 & $-0.0413^{* *}$ & -4.66 & $-0.0175^{* *}$ & -3.90 & $-0.0058^{*}$ & -2.22 \\
\hline L3. & $-0.0110^{*}$ & -2.17 & $-0.0184^{* *}$ & -2.65 & $-0.0137^{* *}$ & -3.25 & $-0.0073^{* *}$ & -2.67 \\
\hline \multicolumn{9}{|l|}{$\sqrt{\nu}^{u}$} \\
\hline L0. & $-0.2586^{*}$ & -1.96 & -0.0033 & -0.03 & -0.0901 & -1.12 & -0.0813 & -1.59 \\
\hline const. & $-0.0217^{*}$ & -2.17 & -0.0032 & -0.35 & -0.0110 & -1.89 & -0.0049 & -1.22 \\
\hline $\operatorname{Adj} . R^{2}$ & \multicolumn{2}{|c|}{$42.25 \%$} & \multicolumn{2}{|c|}{$36.30 \%$} & \multicolumn{2}{|c|}{$33.65 \%$} & \multicolumn{2}{|c|}{$35.55 \%$} \\
\hline
\end{tabular}


Table VIII

\section{Carry Trade Returns: US Measures and Japanese Funding Risk}

This table compares the explanatory and predictive power of Japanese and US measures for monthly AUmJP carry trade returns. For each market, $\nu^{e}$ and $\lambda^{e}$ are the monthly average fitted values of the volatility and jump likelihood, and $\nu^{u}$ and $\lambda^{u}$ are the average residuals (corresponding to the unexpected component of risk). In model (1), we consider the predictive power of Japanese funding risk, by using as independent variables the fitted values (known by investors in the beginning of month) and only lagged residuals. Model (2) shows that the same predictive regression with US measures yields much weaker results. In model (3), for robustness purposes, we use all measures together with changes in TED spread and changes in VIX over the previous month. The t-statistics are computed using robust standard errors and ${ }^{* *}\left({ }^{*}\right)$ shows statistical significance at $1(5)$ percent.

\begin{tabular}{|c|c|c|c|c|c|c|c|}
\hline & & \multicolumn{2}{|c|}{ (1) } & \multicolumn{2}{|c|}{$(2)$} & \multicolumn{2}{|c|}{ (3) } \\
\hline & & Coef. & t-stat & Coef. & t-stat & Coef. & t-stat \\
\hline \multirow[t]{10}{*}{ Japan } & $\lambda^{e}$ & -0.0147 & -1.27 & & & 0.0089 & 0.96 \\
\hline & $\sqrt{\nu}^{e}$ & $-0.2036^{* *}$ & -2.64 & & & -0.0285 & -0.26 \\
\hline & $\lambda^{u}$ & & & & & & \\
\hline & L0. & - & & & & $-0.0381^{* *}$ & -3.21 \\
\hline & L1. & 0.0225 & 1.22 & & & -0.0160 & -1.09 \\
\hline & L2. & -0.0049 & -0.32 & - & - & $-0.0381^{* *}$ & -3.64 \\
\hline & $\sqrt{\nu}^{u}$ & & & & & & \\
\hline & L0. & - & & - & - & -0.1259 & -0.75 \\
\hline & L1. & $0.6280^{* *}$ & 3.82 & & - & 0.1969 & 0.91 \\
\hline & $\mathrm{L} 2$. & $0.4363^{* *}$ & 2.83 & & & 0.0458 & 0.36 \\
\hline \multirow[t]{10}{*}{ US } & $\lambda^{e}$ & - & & $-0.0252^{*}$ & -2.17 & -0.0096 & -0.57 \\
\hline & $\sqrt{\nu}^{e}$ & - & & -0.0461 & -0.58 & -0.0592 & -0.85 \\
\hline & $\lambda^{u}$ & & & & & & \\
\hline & L0. & - & & & - & -0.0003 & -0.01 \\
\hline & L1. & - & & 0.0494 & 1.96 & 0.0355 & 0.90 \\
\hline & L2. & - & & 0.0350 & 1.58 & 0.0074 & 0.26 \\
\hline & $\sqrt{\nu}^{u}$ & & & & & & \\
\hline & L0. & - & & & - & -0.2268 & -1.08 \\
\hline & L1. & - & & -0.0697 & -0.35 & -0.1453 & -0.70 \\
\hline & L2. & - & & 0.2081 & 0.91 & $0.4138^{*}$ & 2.23 \\
\hline \multicolumn{2}{|l|}{$\triangle T E D$} & - & & & & $-0.0244^{* *}$ & -2.72 \\
\hline \multicolumn{2}{|l|}{$\Delta V I X$} & - & & - & & -0.0017 & -1.60 \\
\hline \multicolumn{2}{|l|}{ const. } & $0.0548^{* *}$ & 4.13 & $0.0343^{* *}$ & 2.87 & 0.0185 & 0.87 \\
\hline \multicolumn{2}{|l|}{$\operatorname{Adj} . R^{2}$} & \multicolumn{2}{|c|}{$16.92 \%$} & \multicolumn{2}{|c|}{$2.98 \%$} & \multicolumn{2}{|c|}{$56.91 \%$} \\
\hline
\end{tabular}




\section{Appendix A}

\section{Table A.1 \\ Implied Volatilities across Markets}

This table shows the Black-Scholes implied volatilites for all options. The first column for each country presents the average implied volatility and the second column the corresponding standard deviation. Results are shown for different levels of moneyness and time to maturity. The first column shows the three classes of moneyness considered, where "Low" corresponds to $S / K<0.95$, "Mid" corresponds to $0.95<S / K<1.05$, and "High" corresponds to $S / K>1.05$. The second column refers to time to maturity measured in days. The last row shows the number of option contracts (after filtering) and the number of trading days for each market.

\begin{tabular}{|c|c|c|c|c|c|c|c|c|c|}
\hline \multirow[b]{2}{*}{$S / K$} & \multirow[b]{2}{*}{$T$} & \multicolumn{2}{|c|}{ Australia } & \multicolumn{2}{|c|}{ Japan } & \multicolumn{2}{|c|}{ Switzerland } & \multicolumn{2}{|c|}{ US } \\
\hline & & Mean & St.Dev. & Mean & St.Dev. & Mean & St.Dev. & Mean & St.Dev. \\
\hline \multirow[t]{3}{*}{ Low } & $<45$ & 0.376 & 0.187 & 0.308 & 0.132 & 0.278 & 0.128 & 0.303 & 0.114 \\
\hline & {$[45,90]$} & 0.268 & 0.102 & 0.242 & 0.079 & 0.209 & 0.085 & 0.272 & 0.088 \\
\hline & $>90$ & 0.236 & 0.079 & 0.222 & 0.051 & 0.196 & 0.055 & 0.249 & 0.069 \\
\hline \multirow[t]{3}{*}{ Mid } & $<45$ & 0.281 & 0.186 & 0.251 & 0.110 & 0.195 & 0.089 & 0.226 & 0.103 \\
\hline & {$[45,90]$} & 0.198 & 0.106 & 0.237 & 0.076 & 0.191 & 0.075 & 0.246 & 0.095 \\
\hline & $>90$ & 0.164 & 0.078 & 0.220 & 0.061 & 0.197 & 0.058 & 0.255 & 0.071 \\
\hline \multirow[t]{3}{*}{ High } & $<45$ & 0.387 & 0.234 & 0.313 & 0.129 & 0.256 & 0.092 & 0.305 & 0.112 \\
\hline & {$[45,90]$} & 0.248 & 0.130 & 0.270 & 0.090 & 0.228 & 0.079 & 0.301 & 0.094 \\
\hline & $>90$ & 0.161 & 0.073 & 0.234 & 0.064 & 0.219 & 0.054 & 0.285 & 0.074 \\
\hline \multicolumn{2}{|c|}{ Contracts (days) } & \multicolumn{2}{|c|}{$191,989(2,630)$} & \multicolumn{2}{|c|}{$52,959(2,561)$} & \multicolumn{2}{|c|}{$246,197(2,311)$} & \multicolumn{2}{|c|}{$154,076(2,541)$} \\
\hline
\end{tabular}




\section{Table A.2}

\section{Explaining Monthly Carry Trade Returns with Funding Risk in Switzerland}

This table shows the results of regressing monthly carry trade returns on funding risk, calculated from option data on the Swiss stock market. $\nu^{e}$ and $\lambda^{e}$ are the monthly averages of fitted values for the volatility and jump likelihood. $\nu^{u}$ and $\lambda^{u}$ are the average residuals and correspond to the unexpected component of risk. Four portfolio strategies are shown, AUmJP, HmL, HmL3 and HmL5, with corresponding returns calculated for the period covering January 2000 to December 2011 (for a total of 144 observations). The t-statistics are computed using robust standard errors and $*^{*}(*)$ shows statistical significance at 1 (5) percent.

\begin{tabular}{|c|c|c|c|c|c|c|c|c|}
\hline \multirow[t]{2}{*}{ Strategy } & \multicolumn{2}{|c|}{ AUmJP } & \multicolumn{2}{|c|}{$\mathrm{HmL}$} & \multicolumn{2}{|c|}{ HmL3 } & \multicolumn{2}{|c|}{ HmL5 } \\
\hline & Coef. & t-stat & Coef. & t-stat & Coef. & t-stat & Coef. & t-stat \\
\hline$\lambda^{e}$ & -0.0231 & -0.93 & -0.0202 & -1.01 & -0.0011 & -0.09 & -0.0022 & -0.25 \\
\hline$\sqrt{\nu}^{e}$ & $0.1809^{*}$ & 2.35 & $0.1725^{*}$ & 2.20 & 0.0664 & 1.54 & 0.0333 & 1.02 \\
\hline \multicolumn{9}{|l|}{$\lambda^{u}$} \\
\hline L0. & $-0.0682^{* *}$ & -2.96 & $-0.0541 * *$ & -2.85 & $-0.0335^{* *}$ & -3.12 & $-0.0234^{* *}$ & -3.37 \\
\hline L1. & 0.0225 & 0.53 & 0.0041 & 0.12 & -0.0059 & -0.28 & -0.0006 & -0.05 \\
\hline $\mathrm{L} 2$. & 0.0019 & 0.07 & -0.0220 & -1.03 & -0.0061 & -0.48 & 0.0023 & 0.25 \\
\hline L3. & -0.0011 & -0.05 & -0.0255 & -1.21 & -0.0147 & -1.19 & -0.0046 & -0.54 \\
\hline \multicolumn{9}{|l|}{$\sqrt{\nu}^{u}$} \\
\hline L0. & $-0.4664^{*}$ & -4.37 & $-0.2635^{*}$ & -2.27 & $-0.2509^{* *}$ & -4.48 & $-0.1746^{* *}$ & -3.85 \\
\hline const. & -0.0054 & -0.40 & -0.0055 & -0.50 & -0.0056 & -0.85 & -0.0014 & -0.33 \\
\hline $\operatorname{Adj} . R^{2}$ & \multicolumn{2}{|c|}{$37.75 \%$} & \multicolumn{2}{|c|}{$31.99 \%$} & \multicolumn{2}{|c|}{$29.38 \%$} & \multicolumn{2}{|c|}{$28.08 \%$} \\
\hline
\end{tabular}



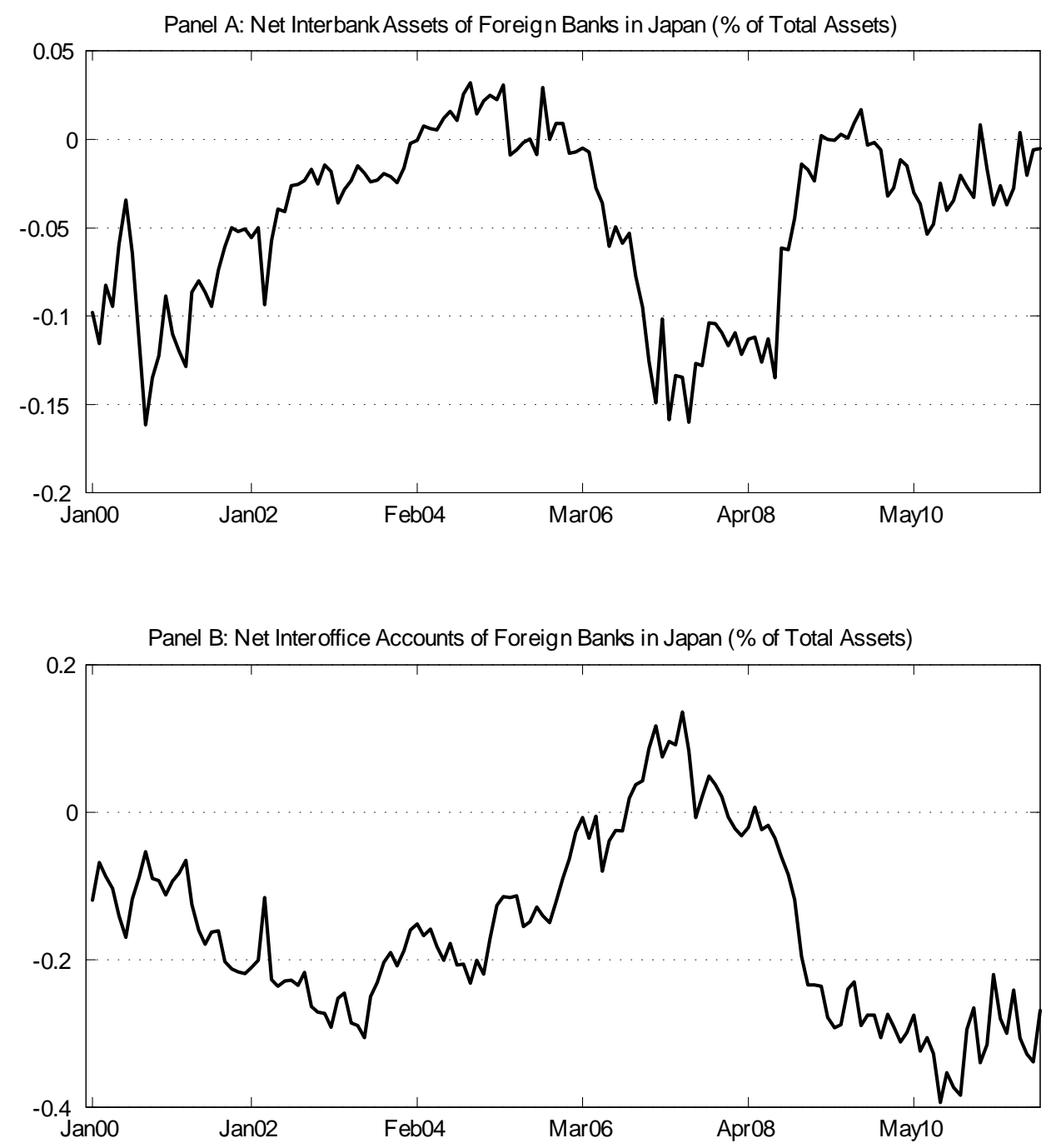

Figure A.1. Balance Sheet Components of Foreign Banks in Japan. Panel A shows the time-series of the monthly net interbank assets of foreign banks in Japan, measured as call loans minus call money and expressed in percentage of the total financial assets of those banks. Similarly, the aggregate net interoffice accounts (Panel B) is measured as the asset minus liabilities interoffice components, expressed as a percentage of total financial assets of those banks. The data is available from Bank of Japan. Over our sample period, the correlation coefficient between the two series is $-65.10 \%$. This strongly negative relation is in line with the findings in Hattori and Shin (2009), and can be interpreted as evidence that the Japan offices of the foreign banks are channeling yen liquidity out of Japan. 


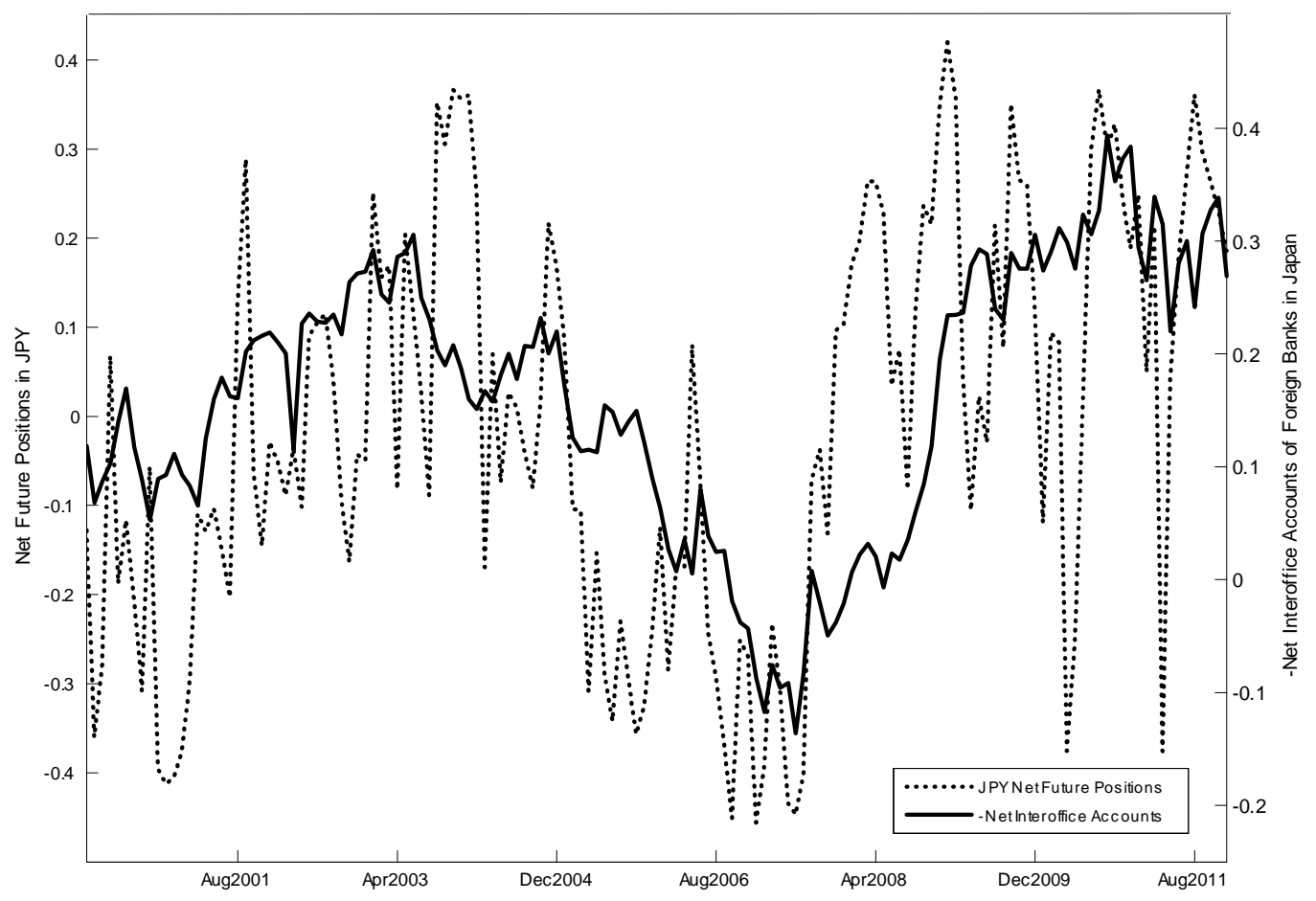

Figure A.2. Carry Trade Activity and Net Interoffice Accounts in Japan. This Figure shows the comovement of the (monthly average) of net future postions in JPY and the (symmetric) of the monthly net interoffice accounts of foreign banks in Japan. The net future positions are calculated as the long minus short futures CFTC position on noncommercial traders in JPY, expressed as a percentage of total open interest of all traders. The aggregate net interoffice accounts of foreign banks in Japan is measured as the asset minus liabilities interoffice components (available from Bank of Japan), expressed as a percentage of total financial assets of those banks. Over our sample period, the correlation coefficient between the net future positions in JPY and the net interoffice accounts is $-51.54 \%$. For illustration purposes, the plot shows the symmetric of the net interoffice accounts (a positive value implies that foreign banks hold a net long position in Japanese assets). 


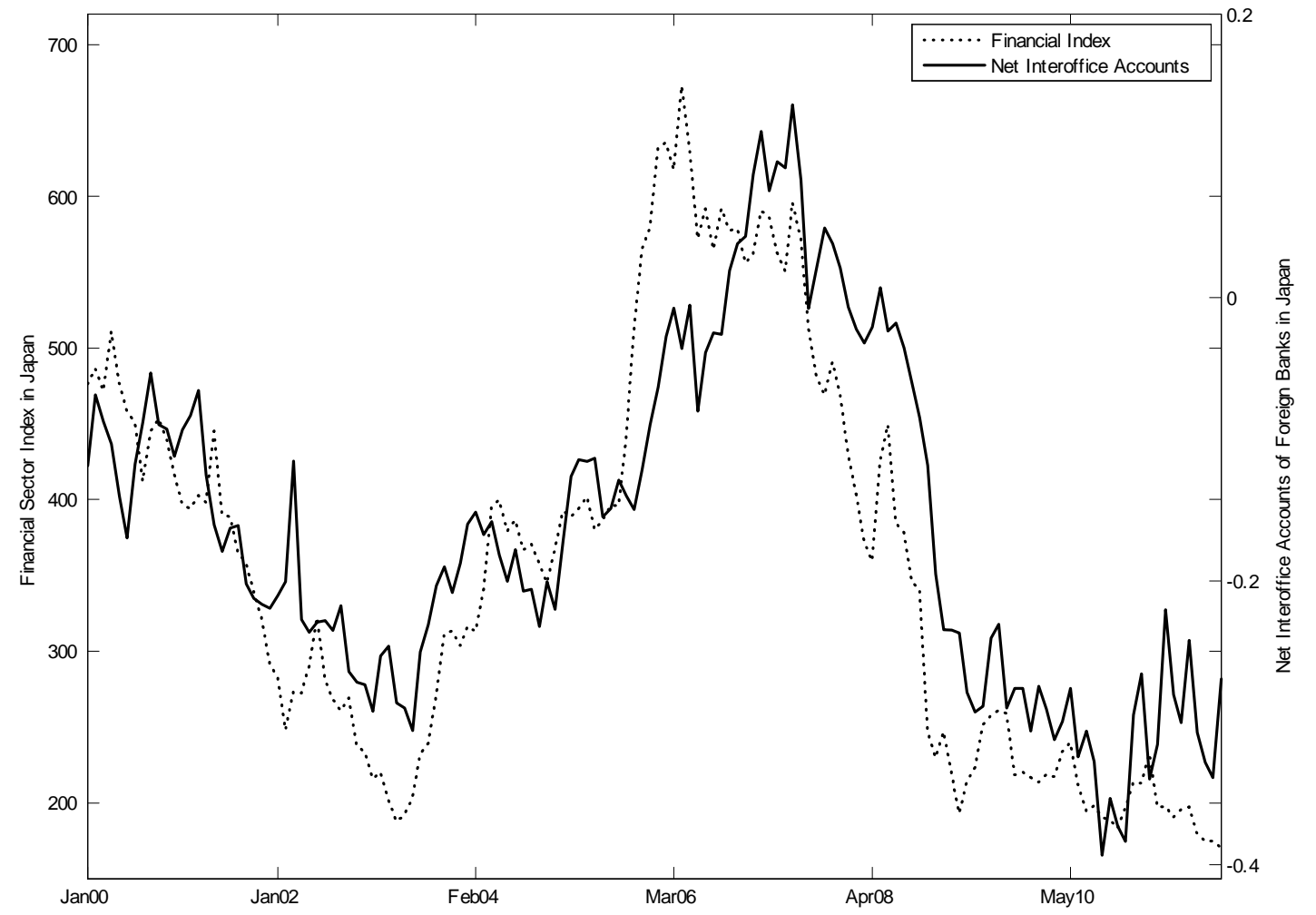

Figure A.3. Financial Conditions in Japan. This Figure shows the comovement of the Japanese financial sector index (taken from Datastream) and the net interoffice accounts of foreign banks in Japan. The aggregate net interoffice accounts of foreign banks in Japan are measured as the asset minus liabilities interoffice components (available from Bank of Japan), expressed as a percentage of total financial assets of those banks. Over our sample period, the correlation coefficient between the two series is $87.23 \%$. 


\section{Appendix B}

In Section I we characterized both the unconstrained and constrained equilibria, ignoring the possibility of switches between the two regimes. In this appendix we fully characterize the equilibrium, by solving for the optimal conditions in the region where the probability of funding constraints being binding is strictly between zero and one. As the distribution of $\pi_{i, t}$ in this case is not Normal, the investors' first order conditions (9) and (8) no longer hold. Therefore we start by determining the new optimality conditions under this more general framework and then calibrate the model and present the simulation results.

Domestic Investors First, given that the funding constraints are not binding for domestic investors, recall that their optimization problem is to choose $\left\{m_{i, t}, b_{i, t}^{d}\right\}$ so as to maximize $-E_{t} e^{-a c_{t+1}}$. Taking first order conditions and using Leibniz rule, it is easy to show that:

$$
\left(1+r_{f}\right) \pi_{i, t}-\frac{A_{i, t}}{\bar{M}_{i}}=\frac{E_{t}\left[\pi_{i, t+1} e^{-a b_{i, t}^{d} \pi_{i, t+1}}\right]}{E_{t}\left[e^{-a b_{i, t}^{d} \pi_{i, t+1}}\right]}
$$

Notice that, in Section I, we were able to further simplify condition (B.1) by using the log-Normal properties. In this case, we have:

$$
\begin{aligned}
E_{t}\left[e^{-a b_{i, t}^{d} \pi_{i, t+1}}\right] & =e^{-a b_{i, t}^{d} E_{t}\left[\pi_{i, t+1}\right]+\frac{1}{2} a^{2}\left(b_{i, t}^{d}\right)^{2} \sigma_{i}^{2}}, \\
E_{t}\left[\pi_{i, t+1} e^{-a b_{i, t}^{d} \pi_{i, t+1}}\right] & =e^{-a b_{i, t}^{d} E_{t}\left[\pi_{i, t+1}\right]+\frac{1}{2} a^{2}\left(b_{i, t}^{d}\right)^{2} \sigma_{i}^{2}}\left(E_{t}\left[\pi_{i, t+1}\right]-a b_{i, t}^{d} \sigma_{i}^{2}\right),
\end{aligned}
$$

and, using expressions (B.2) in (B.1), we obtain condition (9) in the text. ${ }^{21}$

${ }^{21}$ The second equality in conditions (B.2) can be easily derived from the fact that:

$$
E_{t}\left[\pi e^{-a b \pi}\right]=\int \pi \frac{1}{\sigma \sqrt{2 \Pi}} e^{-\frac{(\pi-\mu)^{2}}{2 \sigma^{2}}-a b \pi} d \bar{\pi}=e^{-a b \mu+\frac{1}{2} a^{2} b^{2} \sigma^{2}} \int \pi \frac{1}{\sigma \sqrt{2 \Pi}} e^{-\frac{\left(\pi-\left(\mu-a b \sigma^{2}\right)\right)^{2}}{2 \sigma^{2}}} d \bar{\pi},
$$


Speculators Speculators in country $L$ will choose $\left\{m_{L, t}, b_{L, t}^{s}, b_{H, t}^{s}\right\}$ so as to maximize $-E_{t} e^{-a c_{t+1}}$, subject to $b_{L, t}^{s} \geq-h_{L, t}$. Letting $\lambda_{t}$ be the Lagrange multiplier on the funding constraint and noting that:

$$
\frac{\partial}{\partial b_{L, t}^{s}}\left[E_{t}\left(e^{-a b_{L, t}^{s} \pi_{L, t+1}-a b_{H, t}^{s} \pi_{H, t+1}}\right)\right]=E_{t}\left(-a \pi_{L, t+1} e^{-a b_{L, t}^{s} \pi_{L, t+1}-a b_{H, t}^{s} \pi_{H, t+1}}\right),
$$

we can use the first order conditions for $m_{L, t}$ and $b_{L, t}^{s}$ to obtain:

$$
\left(1+r_{f}\right) \pi_{L, t}-\frac{A_{L, t}}{\bar{M}_{L}}=\frac{E_{t}\left[\pi_{L, t+1} e^{-a b_{L, t}^{s} \pi_{L, t+1}-a b_{H, t}^{s} \pi_{H, t+1}}\right]}{E_{t}\left[e^{-a b_{L, t}^{s} \pi_{L, t+1}-a b_{H, t}^{s} \pi_{H, t+1}}\right]}-\frac{\lambda_{t}}{a E_{t} e^{-a c_{t+1}}},
$$

where $\lambda_{t}\left(b_{L, t}^{s}+h_{L, t}\right)=0$. Similarly for $b_{H, t}^{s}$ :

$$
\left(1+r_{f}\right) \pi_{H, t}-\frac{A_{H, t}}{\bar{M}_{H}}=\frac{E_{t}\left[\pi_{H, t+1} e^{-a b_{L, t}^{s} \pi_{L, t+1}-a b_{H, t}^{s} \pi_{H, t+1}}\right]}{E_{t}\left[e^{-a b_{L, t}^{s} \pi_{L, t+1}-a b_{H, t}^{s} \pi_{H, t+1}}\right]} .
$$

As above, the optimal choice for $b_{i, t}^{s}$ in Section I (given by condition (8)), is a special case of conditions (B.4) and (B.5) above. To see this, note that under the joint normality assumption of $\left(\pi_{L}, \pi_{H}\right)$, we can write $E_{t}\left[e^{-a\left(b_{L, t}^{s} \pi_{L, t+1}+b_{H, t}^{s} \pi_{H, t+1}\right)}\right]$ as:

$$
e^{-a\left(b_{L, t}^{s} E_{t}\left[\pi_{L, t+1}\right]+b_{H, t}^{s} E_{t}\left[\pi_{H, t+1}\right]\right)+\frac{1}{2} a^{2}\left(b_{L, t}^{s}\right)^{2} \sigma_{L}^{2}+\frac{1}{2} a^{2}\left(b_{H, t}^{s}\right)^{2} \sigma_{H}^{2}+a^{2} b_{L, t}^{s} b_{H, t}^{s} \rho \sigma_{L} \sigma_{H}}
$$

and, with some additional algebra, it can also be shown that:

$$
\frac{E_{t}\left[\pi_{i, t+1} e^{-a b_{L, t}^{s} \pi_{L, t+1}-a b_{H, t}^{s} \pi_{H, t+1}}\right]}{E_{t}\left[e^{-a b_{L, t}^{s} \pi_{L, t+1}-a b_{H, t}^{s} \pi_{H, t+1}}\right]}=E_{t}\left[\pi_{i, t+1}\right]-a b_{i, t}^{s} \sigma_{i}^{2}-a b_{j, t}^{s} \rho \sigma_{i} \sigma_{j}
$$

where we drop subscripts and superscripts for ease of notation. 
Equilibrium Conditions Summarizing the conditions above, the system of equilibrium conditions is given by:

$$
\begin{aligned}
\left(1+r_{f}\right) \pi_{L, t}-\frac{A_{L, t}}{\bar{M}_{L}} & =\frac{E_{t}\left[\pi_{L, t+1} e^{-a \pi_{L, t+1} b_{L, t}^{d}}\right]}{E_{t}\left[e^{-a \pi_{L, t+1} b_{L, t}^{d}}\right]}, \\
\left(1+r_{f}\right) \pi_{H, t}-\frac{A_{H, t}}{\bar{M}_{H}} & =\frac{E_{t}\left[\pi_{H, t+1} e^{-a \pi_{H, t+1} b_{H, t}^{d}}\right]}{E_{t}\left[e^{-a \pi_{H, t+1} b_{H, t}^{d}}\right]}, \\
\left(1+r_{f}\right) \pi_{L, t}-\frac{A_{L, t}}{\bar{M}_{L}} & =\frac{E_{t}\left[\pi_{L, t+1} e^{-a b_{L, t}^{s} \pi_{L, t+1}-a b_{H, t}^{s} \pi_{H, t+1}}\right]}{E_{t}\left[e^{-a b_{L, t}^{s} \pi_{L, t+1}-a b_{H, t}^{s} \pi_{H, t+1}}\right]}-\frac{\lambda_{t}}{a E_{t} e^{-a c_{t+1}}}, \\
\left(1+r_{f}\right) \pi_{H, t}-\frac{A_{H, t}}{\bar{M}_{H}} & =\frac{E_{t}\left[\pi_{H, t+1} e^{-a b_{L, t}^{s} \pi_{L, t+1}-a b_{H, t}^{s} \pi_{H, t+1}}\right]}{E_{t}\left[e^{-a b_{L, t}^{s} \pi_{L, t+1}-a b_{H, t}^{s} \pi_{H, t+1}}\right]},
\end{aligned}
$$

together with the market clearing conditions $b_{i, t}^{d}=M_{i, t}^{d}=\frac{\bar{M}_{i}-\left(k_{i}+k_{j}\right) b_{i, t}^{s}}{1-k_{i}}$ and $\lambda_{t}\left(b_{L, t}^{s}+h_{L, t}\right)=$ 0 .

Calibration and Numerical Solution Given the equilibrium conditions defined above, we calibrate the model using the following parameter selection: $\overline{A_{L}}=8.0, \overline{A_{H}}=22.4$, $r_{f}=0.05, \overline{M_{L}}=14.0, \overline{M_{H}}=14.8, \bar{h}=6.7, \sigma_{h}=1.7, k_{L}=k_{H}=0.05, \rho^{U}=0.9, \sigma_{A, L}=1.5$, $\sigma_{A, H}=2, a=1.08, \alpha=0$. For numerically solving the model, we use as initial guesses the equilibrium conditions derived for the cases where the contraints are never binding or always binding. We then search from a wide set of piecewise linear functions for $\pi$ 's and $b_{H}$ 's the ones that most accurately solve the equations in B.8. We rule out mixed equilibria by requiring that $b_{L, t}^{s}=h_{L, t}$ with probability one in the region where the constraints are binding. The resulting simulation plot for each country is shown in Figure 1. 